\title{
Cyclical and Market Determinants of Involuntary Part-Time Employment
}

\author{
Robert G. Valletta \\ Federal Reserve Bank of San Francisco \\ Leila Bengali \\ Yale University \\ Catherine van der List \\ University of British Columbia \\ March 2018 \\ Working Paper 2015-19 \\ http://www.frbsf.org/economic-research/publications/working-papers/2015/19/
}

\section{Suggested citation:}

Valletta, Robert G, Leila Bengali, Catherine van der List. 2018. "Cyclical and Market Determinants of Involuntary Part-Time Employment.” Federal Reserve Bank of San Francisco Working Paper 2015-19. https://doi.org/10.24148/wp2015-19

The views in this paper are solely the responsibility of the authors and should not be interpreted as reflecting the views of the Federal Reserve Bank of San Francisco or the Board of Governors of the Federal Reserve System. 


\title{
Cyclical and Market Determinants of Involuntary Part-Time Employment
}

\author{
Robert G. Valletta* \\ Federal Reserve Bank of San Francisco \\ 101 Market Street \\ San Francisco, CA 94105 \\ (415) 974-3345 \\ rob.valletta@sf.frb.org \\ Leila Bengali \\ Yale University \\ leila.bengali@yale.edu \\ Catherine van der List \\ University of British Columbia \\ catherine.vanderlist@alumni.ubc.ca
}

\section{First version: December 2, 2015 \\ Revised: January 2018 \\ Minor edits: March 2018}

Keywords: part-time employment, business cycle, supply and demand

JEL classification: $\mathrm{J} 22$, J23

\footnotetext{
*Corresponding author. The authors thank FRBSF colleagues, Bob Triest, other Federal Reserve staff, and seminar participants at the University of Wisconsin IRP Summer workshop and the University of Illinois at Urbana-Champaign (School of Labor and Employment Relations) for their comments at various stages of this research. They also thank the editor at Journal of Labor Economics, Paul Oyer, and two anonymous referees for their comments and guidance. Nathaniel Barlow provided helpful research assistance. The views expressed in this paper are solely those of the authors and are not attributable to the Federal Reserve Bank of San Francisco or the Federal Reserve System.
} 


\title{
Cyclical and Market Determinants of Involuntary Part-Time Employment
}

\author{
$\underline{\text { Abstract }}$ \\ The fraction of the U.S. workforce identified as involuntary part-time workers rose to new highs \\ during the U.S. Great Recession and came down only slowly in its aftermath. We assess the \\ determinants of involuntary part-time work using an empirical framework that accounts for \\ business cycle effects and persistent structural features of the labor market. We conduct \\ regression analyses using state-level panel and individual data for the years 2003-2016. The \\ results indicate that the persistent market-level factors, most notably shifting industry \\ composition, can largely explain sustained elevation in the incidence of involuntary part-time \\ work since the recession.
}




\section{Cyclical and Market Determinants of Involuntary Part-Time Employment}

\section{Introduction}

Part-time employment is common in the United States. Since the mid-1990s, on average slightly more than one in six U.S. civilian employees worked part-time hours, defined as fewer than 35 hours per week. In their tracking of part-time employment, the U.S. Bureau of Labor Statistics (BLS) distinguishes between individuals who work part time voluntarily ("noneconomic reasons") and those who work part time involuntarily ("economic reasons"). Although the voluntary part-time group is much larger, interest in the involuntary part-time group has increased in recent years as its share of the workforce reached unusually high levels during the Great Recession of 2007-2009. Moreover, as the U.S. economy recovered from that recession, the level of involuntary part-time work remained relatively high.

Some policymakers and analysts have raised the possibility that the persistent elevated level of involuntary part-time work in the United States represents labor underutilization, or labor market "slack," beyond that reflected in the unemployment rate (e.g., Yellen 2014; Blanchflower and Levin 2015). This interpretation has been raised for other countries as well (e.g., Bell and Blanchflower 2014; IMF 2017) Alternatively, elevated involuntary part-time employment may reflect labor market changes that are independent of the business cycle and hence persistent, such as the ongoing shift to a service-based economy and the growth of the ondemand or "gig” economy (Golden 2016; Bracha and Burke 2017).

In this paper, we examine the determinants of involuntary part-time work, distinguishing between variation associated with the aggregate business cycle and variation attributable to more persistent structural features of the labor market. Existing research on the characteristics and 
behavior of involuntary part-time workers is relatively limited in quantity and scope. A small literature from the 1980s and 1990s focused on identifying the behavioral distinction between voluntary and involuntary part-time work and provided information on a limited set of explanatory factors (Stratton 1996; Leppel and Clain 1988, 1993; Fallick 1999; Tilly 1991). A number of recent studies provided descriptive analyses of involuntary part-time work and examined the potential impact of the Affordable Care Act's requirement that large employers provide health insurance to full-time workers (e.g., Cajner, Mawhirter, Nekarda, and Ratner 2014; Canon, Kudlyak, Luo, and Reed 2014; Robertson and Terry 2014; Golden 2016; Even and Macpherson 2017; Dillender, Heinrichs, and Houseman 2016; Garrett, Kaestner, and Gangopadhyaya, 2017; Mathur, Slavova, and Strain 2016; Moriya, Selden, and Simon 2016). Borowczyk-Martins \& Lalé $(2016,2017)$ used data on flows between labor market states to illustrate the rising importance of transitions between full-time and involuntary part-time jobs over business cycles and also over the longer term in the United States and the United Kingdom. We expand on existing research by developing a general empirical framework for understanding changes in the incidence of involuntary part-time work and assessing the quantitative impact of key explanatory factors for the years 2003 through 2016. As we show below, changes in aggregate workforce composition do not make a meaningful direct contribution to changes in the level of involuntary part-time work over our sample frame. We therefore rely on state-level panel data for our primary empirical analyses. Importantly, this framework enables us to jointly model and hence properly distinguish between changes in cyclical labor market conditions at the state level and changes in structural features of state labor markets and the composition of their workforces. The structural features include demand and supply determinants of involuntary part-time work, in particular industry employment shares, 
labor costs, and workforce demographics. Unlike a conventional composition adjustment, which accounts only for changes occurring within groups, our regression framework identifies the overall effects of changing workforce composition based on underlying shifts in demand and supply for part-time work. The cyclical and structural market factors that we identify can largely account for the aggregate changes in involuntary part-time work observed during the Great Recession of 2007-2009 and its aftermath.

Our analysis proceeds as follows. We begin in Section II by defining the relevant concepts and patterns regarding part-time employment and providing descriptive statistics derived from monthly Current Population Survey (CPS) data. In addition to identifying the facts to be explained, the descriptive calculations serve a dual purpose for motivating the subsequent analyses. First, they establish that changes in workforce composition do not directly explain changes in involuntary part-time employment over our sample frame. Second, they provide the basis for our conceptual framework described in Section III, which highlights the importance of cyclical conditions and the structural market factors noted above.

Section IV provides empirical results based on our state panel framework. We start with additional descriptive analyses that identify patterns across states and over time in involuntary part-time work and potential explanatory factors, including unemployment rates, industry shares, labor costs, and demographic composition; these analyses motivate and guide our regression specification. The regression analyses based on the state panel data confirm the importance of cyclical and structural market factors to changes in involuntary part-time work over time. We probe these results further in Section V, using the CPS microdata merged to the state panel data. The results based on the microdata reinforce the findings from the state panel and provide additional insights regarding the relationship between involuntary part-time work and the gig 
economy. In Section VI, we use the state panel regression results to provide a detailed decomposition of the contributions of the cyclical and market factors to changes in the aggregate rate of involuntary part-time employment.

To preview, our results show that the cyclical component accounts for a large portion of the variation over time in the incidence of involuntary part-time work. However, continued elevation in the rate of involuntary part-time work through 2016 is largely attributable to other more persistent features of state labor markets, mainly changes in industry employment shares. We interpret these findings and note implications for future research in Section VII.

\section{Patterns in Involuntary and Voluntary Part-Time Work (IPT and VPT)}

We begin by defining terms and providing descriptive statistics that establish the facts about involuntary part-time work that we seek to explain, along with related patterns in voluntary part-time work. Similar descriptive statistics have appeared in other existing work. We repeat some of those here but extend and tailor them to provide a comprehensive basis for our subsequent analyses. ${ }^{1}$

\section{A. Definitions and Aggregate Patterns over Time}

Data on part-time work are available from the BLS, based on CPS data. The CPS is the monthly household survey conducted by the U.S. Census Bureau for the BLS, and it is used for calculating official labor force statistics such as labor force status, unemployment, and work hours. In this sub-section, we examine patterns over time in the official BLS part-time work series.

\footnotetext{
${ }^{1}$ Golden (2016) provides the most comprehensive descriptive analysis and discussion, with breakdowns of IPT work by industries, occupations, and demographic groups. Similar but less comprehensive breakdowns are provided in Cajner et al. (2014), Canon et al. (2014), and Robertson and Terry (2014).
} 
As noted earlier, part-time work is defined as fewer than 35 hours per week. This refers to hours at all jobs, so an individual who works multiple jobs and reaches at least 35 total hours in a week will not be identified as a part-time worker. The CPS survey distinguishes between two broad groups of persons who work part time. The first is those working part time for "noneconomic" reasons, or voluntarily. These are workers whose part-time status represents a labor supply decision (hence "noneconomic reasons" is a slight misnomer): they prefer a parttime job for personal reasons such as family obligations, school, or partial retirement. ${ }^{2}$ Of the 15 to 20 percent of employed people who work part time, about three-fourths are in this category. The other category is those working part time for "economic" reasons, or involuntarily. This includes workers who report that they would like a full-time job but cannot find one due to constraints on the employer side of the labor market, such as a cutback in hours at their current job ("slack work") or an inability to find full-time work (which are separately distinguished in the data). ${ }^{3}$ As such, involuntary part-time work primarily reflects labor demand considerations. More precisely, involuntary part-time work reflects that the number of jobs in which only parttime hours are offered exceeds the number of employed individuals who prefer part-time over full-time schedules.

Past research has found the distinction between voluntary and involuntary part-time work to be meaningful, based on the greater tendency for involuntary part-time workers to be working full-time in the future than is the case for voluntary part-time workers (Stratton 1996). However, the prevalence of voluntary part-time work may affect involuntary part-time work through the

\footnotetext{
${ }^{2}$ As indicated in the monthly BLS employment reports, noneconomic reasons include "childcare problems, family or personal obligations, school or training, retirement or Social Security limits on earnings, and other reasons."

${ }^{3}$ More precisely, economic reasons include "slack work or unfavorable business conditions, inability to find full-time work, or seasonal declines in demand."
} 
interaction of market-level demand and supply factors for jobs that provide part-time hours (discussed further in Section III). We therefore examine descriptive statistics for both types of part-time work. ${ }^{4}$ In the remainder of the paper, we will refer to involuntary part-time work as IPT and voluntary part-time work as VPT.

Figures 1 and 2 illustrate the time-series patterns in IPT, VPT, and their sum. These figures rely on the published BLS series, expressed as a share of total civilian employment and measured on a monthly basis for the period 1994 through the end of $2016 .{ }^{5}$ Figure 1 shows that the prevalence of VPT employment has been largely stable over the past few decades, including during the Great Recession and its aftermath. By contrast, the incidence of IPT employment rose substantially during the Great Recession and fell slowly in subsequent years. This countercyclical pattern also was evident but less pronounced around the 2001 recession. The strong counter-cyclicality in IPT employment combined with the non-cyclical VPT series generates counter-cyclicality in overall part-time work in Figure 1.

Figure 2 provides additional information on cyclical patterns in IPT by displaying the overall series (Panel A) and its sub-components (Panel B) against the unemployment rate. Panel A shows that the IPT rate typically tracks the unemployment rate entering recessions, suggesting

\footnotetext{
${ }^{4}$ The sum of the two series differs slightly from the BLS measure of overall part-time work because the overall series is based on usual weekly work hours while the VPT and IPT components are based on hours worked during the survey reference week. Usual and actual hours worked may differ for various reasons, such as daily schedule variation in jobs where workers are on call or inconsistent availability of overtime hours. For example, an individual whose usual weekly work schedule includes 30 hours may be IPT in a typical week but full-time in a week in which they are offered and accept at least 5 hours of additional shifts or overtime work.

${ }^{5}$ There is a break in the involuntary and voluntary part-time work series in 1994 due to a change in CPS survey procedures and definitions that tightened the IPT criteria. The revised survey required those identified as IPT to state explicitly that they want and are available for full-time work, rather than inferring this from their responses to related questions. This break produced a significant shift in overall part-time employment and the relative levels of the IPT and VPT series (Polivka and Miller 1998; Valletta and Bengali 2013; Borowczyk-Martins \& Lalé 2016).
} 
that both series largely reflect labor market slack. However, the decline in the IPT rate has lagged declines in the unemployment rate, with the lag especially evident in the aftermath of the Great Recession.

Panel B of Figure 2 displays the two sub-components of the IPT series. The "slack work" component refers to individuals whose work hours were reduced due to weak demand, while the other component represents individuals who report that they can only find part-time work. The slack work component shows a pronounced cyclical pattern, moving up and down with the overall unemployment rate, especially around the Great Recession. The component representing an inability to find full-time work also rose significantly during the Great Recession and has shown only a slow recovery since then, especially during the early recovery years of 2010-14. At the end of 2016, both IPT components exceeded their pre-recession lows by a larger amount than did the unemployment rate. ${ }^{6}$

These patterns of IPT prevalence by component are consistent with the results on flows between full-time and part-time employment identified by Borowczyk-Martins \& Lalé (2016). They show that cyclical movements in IPT are dominated by an increased flow rate from fulltime to part-time work without an intervening change in employer or spell of unemployment. This is consistent with the pronounced cyclical pattern in the IPT "slack work" component. They also find that these patterns have intensified on a secular basis since the mid-1990s, as the probability of moving directly from full-time to part-time employment rose substantially more than the converse transition probability. This is consistent with the continued elevation of the "inability to find full-time work" component in the aftermath of the Great Recession and with a

\footnotetext{
${ }^{6}$ The unemployment rate reached a low of 4.4 percent before the Great Recession and was at 4.7 percent at the end of 2016. The corresponding figures are 1.7 percent and 2.3 percent for the IPT "slack work" component and 0.8 and 1.3 percent for the "could only find PT work" component.
} 
higher level of IPT in steady state.

\section{B. Comparisons across Groups (CPS Microdata)}

We provide additional descriptive analyses in this sub-section using the publicly available CPS microdata, which we also use for later regression analyses that supplement our state panel analyses (Section V). Our primary analysis period is 2003 through 2016. This period largely covers the business cycle associated with the Great Recession, enabling us to distinguish between purely cyclical versus persistent structural factors that may affect the level of involuntary part-time work. Importantly, the restriction to 2003-forward eliminates the distorting influence of major changes in industry category definitions applied to the CPS microdata and payroll employment data (used in our state panel regressions) in the early 2000 s. $^{7}$

The CPS surveys about 60,000 households each month, yielding information on hours worked and related variables for samples of about 50-60,000 employed individuals per month, based on our sample restrictions. We limit our empirical analyses to individuals age 16 and over who are employed in nonagricultural jobs and were at work during the reference week. In addition to wage and salary workers, we include the unincorporated self-employed in our sample to account for the potential influence of the informal or "gig" economy on part-time work. Following most work that focuses on hours and wages using CPS data, we exclude observations with imputed (allocated) values of hours worked (see e.g. Buchmueller, DiNardo, and Valletta 2011). The resulting sample size for our analyses is slightly under 9.5 million observations.

Table 1 provides a breakdown of IPT and VPT rates, plus their sum, across labor market

\footnotetext{
${ }^{7}$ The industry re-definitions caused by the switch to the 2000 NAICS codes substantially altered the definitions and employment shares for key industries for our analyses, notably retail and personal services. In addition, our state level analyses rely on estimates of IPT employment calculated from published BLS figures on alternative measures of labor underutilization at the state level, which only became available beginning in 2003.
} 
groups and sectors. We list tabulations for three years: 2005, 2010, and 2016. The beginning and end years largely span the sample frame for our subsequent analyses and also represent years with similar aggregate labor market conditions (but a higher IPT rate in the latter year). ${ }^{8}$ The middle year, 2010, represents a labor market trough measured on an annual basis, with the average unemployment and IPT rates for the year reaching cyclical highs of 9.6 and 6.6 percent. The calculations for the complete sample yield IPT and VPT fractions that are very close to official BLS data releases, with small variation attributable to our sample restrictions.

The figures listed in Table 1 refer to the group-specific employment share by part-time status, which can be compared to the "All Workers" total in the first row. ${ }^{9}$ For reference purposes, the final three columns provide the share of each group in overall employment.

Table 1 shows a relatively consistent pattern over time across the various age/gender, education, and racial/ethnic groups. IPT work rose substantially between 2005 and 2010 and then fell substantially by 2016 (columns 1-3). However, for virtually all groups, with the exception of individuals employed in a small subset of industries and occupations, the 2016 levels of IPT work remained well above the 2005 levels. By contrast, the change in VPT work was mixed across groups, and on balance its prevalence was essentially unchanged between 2005 and 2016 (columns 4-6). Given the general increase in IPT work, the sum of VPT and IPT was slightly higher in 2016 than in 2005 (columns 7 and 9). Employment in both categories of part-time work is generally higher for lower skill workers, especially the young. The employment shares in the

\footnotetext{
${ }^{8}$ The U.S. unemployment rate averaged 5.1 percent in 2005 and 4.9 percent in 2016, with slightly more rapid payroll employment growth in the earlier year. The IPT rate was 3.1 percent in 2005 and 3.9 percent in 2016.

${ }^{9}$ For example, the number in the second row, first column of the table indicates that 5.8 percent of employed individuals age 16-24 were involuntary part-time workers in 2005, while the fourth column indicates that 35.3 percent of that group were voluntary part-time workers in 2005; the remaining 58.9 percent were employed full-time.
} 
final two columns show declines over our sample period for some age/gender groups with high rates of part-time work (e.g., 16-24 year olds) and increases for others (e.g., age 65 and over). ${ }^{10}$ The VPT rate for individuals age 65 and over is very high compared with other groups, likely reflecting partial retirement in which part-time work has substituted for full-time career jobs, but it declined substantially over our sample frame.

As noted in the Introduction, trends in part-time work may relate to the growth of work hours in jobs that do not involve a formal employer-employee relationship, in particular through the provision of services in the on-demand or gig economy (Bracha and Burke 2017). Katz and Krueger (2017) examined administrative data from tax filings and found that the incidence of such work rose substantially between 2005 and 2015. As discussed in Abraham, Haltiwanger, Sandusky, and Spletzer (2017), gig work should primarily be reflected in the incidence of unincorporated self-employment in public-use data sources such as the CPS. Our tabulations at the bottom of the first page of Table 1 show that the unincorporated self-employed have high rates of IPT and VPT. However, consistent with the findings of Abraham et al., our tabulations show that gig work is not well measured in the CPS: in contrast to Katz and Krueger's finding of sharply rising alternative or gig work, the incidence of unincorporated self-employment has been declining. Thus, trends in gig employment cannot explain any rising tendency to work part time in our CPS data. ${ }^{11}$ However, the table also shows that multiple job holders, and the subset selfemployed on their second job, have a relatively low incidence of IPT and VPT. This suggests

\footnotetext{
${ }^{10}$ We group men and women together in the youngest and oldest age categories, because their rates of IPT are similar within these age groups and the aggregated categories improve the statistical precision of our subsequent estimates.

${ }^{11}$ Table 1 shows that the share of the unincorporated self-employed who are IPT or VPT rose over our sample frame. However, the share of workers who are unincorporated self-employed fell by an offsetting amount, leaving the share of the workforce composed of unincorporated self-employed workers of both part-time groups largely unchanged.
} 
that some workers may seek out gig work as a means to achieve full-time hours. We examine this relationship further in Section V-B.

The second page of Table 1 shows substantial variation across broad industries and occupations in the incidence of part-time work. Both IPT and VPT work are especially high in selected services industries, such as retail and especially leisure and hospitality (including restaurants) and other services (mostly consisting of personal services, such as barber and beauty shops, dry cleaning, repair services, etc.). By contrast, part-time work of both types tends to be low in manufacturing and related industries such as wholesale trade and transportation. A slow shift in employment over time away from manufacturing and toward the services industries that rely more heavily on part-time labor is evident in the employment share comparisons displayed in the final three columns of the table. This shift toward service industries may put upward pressure on the overall proportion of part-time jobs in the work force. Similar patterns in parttime work and the shift toward selected service activities also are reflected in the tabulations by broad occupational category. However, the shift toward industry and occupation categories with high incidence of IPT and VPT is not uniform: for example, employment shares for the retail trade sector and the closely related sales occupation are each declining.

The tabulations in Table 1 raise the possibility that shifts in workforce composition may have directly affected the incidence of IPT and VPT over our sample frame. However, the increase in IPT over our sample frame and relative stability in VPT is evident across essentially the entire range of employment categories listed in Table 1, suggesting a limited impact of changing workforce composition. For example, in virtually every broad industry, the level of IPT was higher in 2016 than in 2005, substantially so in industries that rely most heavily on part-time 
labor (retail, leisure and hospitality). ${ }^{12}$

To formally assess the contributions of compositional shifts to the aggregate patterns in part-time work, we calculated a composition-constant counterfactual using a standard reweighting technique (DiNardo, Fortin, and Lemieux 1996; Daly and Valletta 2006). The reweighting holds constant the composition of the sample at base year values, generating counterfactual calculations of the IPT and VPT rates under the assumption that workforce composition is unchanged from a selected base year. We used a detailed compositional breakdown that includes complete interactions between age, gender, marital status, and education attainment categories, plus race/ethnicity, industry, and occupation separately. ${ }^{13}$ We hold the composition of the workforce based on these measures to its 2003 distribution, with reweighting applied to each subsequent set of annual observations.

The results of this analysis are displayed in Appendix B (Figure B1). Changes in workforce composition explain virtually none of the change over time in the incidence of either type of part-time work: the actual and adjusted (composition constant) lines are nearly identical across the entire sample frame. The primary exceptions are the few years early in the recovery from the recession: the adjusted values exceed the actual values by a small margin, indicating that compositional changes on balance slightly reduced the rates of part-time work in those

\footnotetext{
${ }^{12}$ The exceptions are manufacturing and professional and business services, in which the IPT rate was essentially the same in 2005 and 2016.

${ }^{13}$ This technique is closely related to standard shift-share analyses, in which an aggregate rate is adjusted by holding group shares constant and recalculating the aggregate using the observed group-specific rates. A key advantage of the reweighting approach is that it accommodates high dimensionality and extensive overlap in the underlying groups used to define compositional changes. We therefore are able to adjust for even more detailed composition categories than are listed in Table 1. Specifically, we interacted the seven age groups shown in the table with gender, marital status (married with spouse present, or not), and five educational attainment categories, for a total of 140 demographic categories across which individuals are likely to differ significantly in their propensities to work part time. The adjustment also includes the five race/ethnicity categories and the complete sets of major industry and major occupation categories displayed in Table 1.
} 
years. The absence of meaningful composition effects reflects offsetting contributions from the underlying compositional elements (e.g., the growing share of leisure and hospitality vs. the declining share of retail, growth in the older population vs. decline in the youngest group, etc.).

On balance, the descriptive analyses illustrate substantial differences over the business cycle and time, and also across labor market groups, in the incidence of involuntary and voluntary part-time work. They also indicate that changes in IPT over time are not explained by direct effects of changing workforce composition. In the next section, we discuss potential factors underlying these changes in IPT work, which provide a basis for additional empirical assessment in subsequent sections.

\section{Understanding Involuntary Part-Time Work: A Conceptual Framework}

The empirical patterns illustrated and discussed in the preceding section shed light on the determinants of part-time work. We can usefully divide the determinants into two categories: (i) changes in labor demand occurring at a business cycle frequency; and (ii) longer term changes in workforce structure and conditions, such as industry and demographic composition. We will refer to the first category as "cyclical" factors and the second as "market" factors. We will also use the terms "structural" and "secular" to refer to the latter category; its key feature is slow movement in the underlying factors, reflecting persistent changes in demand and supply conditions rather than variation at a business cycle frequency.

The role of cyclical factors was evident in Figures 1 and 2 in the previous section. They showed that the IPT rate moves counter-cyclically, with an especially large movement during the Great Recession of 2007-09 and its aftermath. Existing literature has identified a number of reasons for counter-cyclicality in IPT work, revolving around its role as an adjustment 
mechanism in response to economic shocks. Friesen (1997) empirically examined the trade-off between part-time and full-time work using U.S. CPS data and found that firms in industries that rely heavily on part-time labor tend to adjust its use relatively rapidly in response to economic shocks. One compelling reason for this pattern is to minimize current and future turnover costs by relying on hours adjustments for current staff rather than changes in head counts.

The analysis of Borowczyk-Martins and Lalé $(2016,2017)$ provides empirical support for this adjustment mechanism. They show that during the U.S. Great Recession the increase in IPT was largely associated with increased direct flows from full-time to part-time employment without a change in employer, consistent with the view that employers used part-time employment to reduce hours worked without incurring turnover costs. As they also note, individuals who prefer to work full-time might be more willing to accept part-time work in a downturn, when the value of their outside option declines, thereby reinforcing the employer shift toward part-time labor. These factors also will tend to cause IPT to decline during economic recoveries, as workers' outside options improve and employers can avoid hiring costs by increasing work hours of existing staff. The pronounced countercyclical pattern in the "slack work" component of IPT shown earlier in Figure 2B is consistent with this narrative.

Such cyclical adjustments in part-time work may be reinforced by experience rating in the U.S. unemployment insurance (UI) system. By reducing hours rather than laying off workers, firms avoid the additional UI taxes that are incurred proportional to their layoff history (Borowczyk-Martins and Lalé 2018). Moreover, even during a recovery period, if demand uncertainty or volatility is high, greater reliance on part-time employees may be a cost-effective 
means for enhancing employment flexibility (Euwals and Hogerbrugge 2006). ${ }^{14}$

Turnover costs and related factors constitute labor market frictions that generate IPT, much like search-and-matching frictions in standard models of equilibrium unemployment. The discussion above suggests that these frictions are likely to become more prominent in downturns, generating cyclical movements in IPT as an additional form of labor market slack beyond movements in the unemployment rate. This is reinforced by frictions in the coordination of work hours that preclude continuous hours adjustment, as reflected in frameworks to model the discrete tradeoff between full-time and part-time labor (e.g., Chang, Kim, Kwon, and Rogerson 2011).

The second, broader category of IPT determinants includes market factors that evolve much more slowly than the business cycle. These factors include industry structure, labor costs, and workforce demographics, each of which could affect the relative demand and supply for part-time work and consequently the level of involuntary part-time work. ${ }^{15}$

As established in the preceding section (Table 1), VPT and IPT rates vary substantially across industries. One reason for such differences is a "peak-load" pattern in which demand is predictably high at certain limited times during the day (e.g., a lunch or dinner rush at a restaurant). Although full-time workers can be repurposed between peak periods to some degree, relying on part-time workers (e.g., 4 to 5 hour shifts) is one cost-effective approach to meeting peak-load demands. Such patterns are widespread in the retail and hospitality sectors. If the employment share of industries with such peak-load characteristics rises, employer demand for

\footnotetext{
${ }^{14}$ Available evidence suggests that employer uncertainty was high during the Great Recession and recovery (Baker, Bloom, and Davis 2016).

${ }^{15}$ Abhayaratna, Andrews, Nuch, and Podbury (2008) discuss these considerations in the Australian context.
} 
part-time labor will rise as well (see Euwals and Hogerbrugge 2006). Such changes may be evident at the occupation level as well, although because the relevant technologies are primarily industry based, changes in industry are likely to be more closely related to changes in IPT than changes in occupation. We explore this issue further in our empirical analyses below.

Another potential source of changes in demand for part-time labor is labor costs. If the per-hour costs of employees increase, employers may reduce work hours by shifting from fulltime to part-time labor and also substituting capital for labor. ${ }^{16}$ Given that many part-time jobs are low skill and concentrated in the retail and services sectors, the level of the minimum wage may be an important element of labor costs. Employers' cost of employee health benefits is another element of labor costs that may be relevant for the use of part-time labor, particularly given that part-time employees often are excluded from employer health benefit plans (Carrington, McCue, and Pierce 2002).

The impact of employer health benefits on the incidence of IPT work may have been affected in recent years by the 2010 passage of the Affordable Care Act (ACA). The law includes a mandate that employers with at least 50 full-time employees must provide health benefits to employees who work at least 30 hours per week or pay a penalty. The mandate was originally scheduled for implementation in 2014 but was delayed to 2015-16. Employer adjustments to the mandate may have occurred prior to its implementation. Analysis to date has produced conflicting results about ACA effects on part-time work. ${ }^{17}$

\footnotetext{
${ }^{16}$ Part-time wage rates are typically less than full-time wage rates, which lowers employers' costs of hiring part-time workers. Much of the wage gaps appears to be explained by the observable characteristics of part-time versus full-time workers and jobs, although existing research suggests that a substantial gap remains after accounting for these differences (e.g., Hirsch 2005).

${ }^{17}$ Even and Macpherson (2017) and Dillender et al. (2016) find evidence supporting the view that the ACA employer mandate has increased the level of IPT work, whereas Garrett, Kaestner, and
} 
On the supply-side of the labor market, changing demographics may affect the availability of part-time labor (see the discussion of Table 1 in section II-B). Young workers are a key source of VPT, but their share in the workforce and population has been declining. This may cause employers seeking part-time employees to rely more heavily on demographic groups who prefer full-time work, thereby increasing the incidence of IPT. By contrast, workers age 65 and over have a very high incidence of part-time work. Their share of the workforce has been growing, but as shown in the previous section they have been exhibiting a declining tendency to work part time. The net impact of such demographic changes is ambiguous.

The demand and supply factors that we have identified tend to evolve slowly over time and are likely to vary across different geographic markets. If the demand factors increase aggregate demand for part-time labor while the supply of workers who prefer part-time work is constant or declining, the result is likely to be an increase in the incidence of involuntary parttime work. For example, if relatively rapid employment growth in the leisure and hospitality sector increases overall employer demand for part-time labor in a particular geographic market, an increase in IPT may result unless there is corresponding growth in supply via demographic groups that supply large amounts of part-time labor.

In a frictionless labor market, relative wages should adjust to clear the markets for fulltime and part-time labor, eliminating the incidence of IPT. In actual labor markets, however, frictions generate IPT as a persistent or equilibrium phenomenon. In addition to the frictions related to turnover costs and hours coordination noted above, with inelastic labor supply to parttime and full-time work, or more general downward wage rigidity, relative wages will adjust

Gangopadhyaya (2017), Mathur, Slavova, and Strain (2016) and Moriya, Selden, and Simon (2016) do not. 
slowly to changing market conditions. ${ }^{18}$ Moreover, workers choosing between part-time and fulltime employment tend to be low skill, hence the minimum wage may be a binding constraint on the decline in the relative wage paid for full-time work. As such, changes in IPT due to slowly evolving changes in demand and supply conditions are likely to persist.

Assessing the impact of such changes on the incidence of IPT work requires an approach that jointly accounts for the changing demand and supply factors. If they are not jointly included in the analysis, their respective roles may be distorted: for example, in the hypothetical scenario described two paragraphs above, the role of industry shifts may be confounded by offsetting changes in demographic composition. Importantly, composition adjustments such as that conducted in Section II-B do not meet the joint accounting requirement: they can adjust for changes in the numbers of IPT and VPT workers within categories but cannot account for demand and supply interactions across categories, or within-category changes in the factors that determine the incidence of IPT. Accurate assessment of the slowly evolving market determinants also requires proper accounting for the large cyclical component discussed above.

Given these considerations, assessment of the factors underlying changes in IPT requires variation over time or across units in cyclical labor market conditions and identifiable demand and supply factors. Because aggregate time-series data are not adequate to separately identify the various determinants of IPT employment described in this section, the remainder of the paper discusses an empirical framework that relies on variation in cyclical conditions and market factors measured at the state level. ${ }^{19}$

\footnotetext{
${ }^{18}$ See Daly and Hobijn (2014) for empirical evidence on downward nominal wage rigidity.

${ }^{19}$ Recent research has described changing patterns of part-time work in other countries. In addition to Borowczyk-Martins and Lalé's (2017) joint analysis of IPT in the United States and the United Kingdom, other recent work has examined the elevated level of IPT in the United Kingdom, focusing on its implications for the measurement of labor market slack in the aftermath of the 2008-09 recession (e.g., Bell and Blanchflower 2014). In a similar vein, rising part-time work on a cyclical and trend basis in
} 


\section{Regression Analyses Using State Panel Data}

The preceding discussion identified cyclical and market factors that are likely to affect the prevalence of IPT work and emphasized that geographic variation may be exploited to assess their roles. Although narrow geographic areas may provide the best market definition to assess the influence of these factors, the required data are most readily available at the state level (51 units, including the District of Columbia). In this section, we describe our state panel data approach. Because cross-state variation in IPT and related variables has not been exploited in other work on part-time employment - other than in very brief and preliminary form in Valletta and van der List (2015) — we start with a descriptive analysis of patterns in these data (Section A) and then proceed to our regression framework and results (Section B).

\section{A. Data Description}

Our state panel dataset consists of annual observations on IPT employment rates and possible explanatory factors covering the period 2003 through 2016. In addition to the state unemployment rates and other indicators of business cycle conditions in each state, including labor force participation rates and state GDP growth, we incorporate data series that reflect the market factors discussed in Section III: ${ }^{20}$

(1) Industry employment shares. Our regression analyses in the next sub-section include a complete set of broad industry categories.

(2) State labor costs. We use data on the level of real wages (median and other percentiles)

Australia has been identified and discussed by staff at that country's central bank (Cassidy and Parsons 2017). The International Monetary Fund recently provided a broad cross-country assessment of trends in IPT work, finding that it remains somewhat elevated in most advanced economies, even those where unemployment has largely returned to pre-recession levels (IMF 2017).

${ }^{20}$ See Appendix A for additional details on state data sources and definitions. 
and the legislated state minimum wage (measured as a fraction of the state nominal median wage).

(3) Population and labor force shares by age group and gender.

The descriptive analyses in Section II suggested that the key determinant of IPT rates over time is the state of the business cycle. Cyclical conditions in the labor market are most commonly described by the unemployment rate. Figure 3 displays the relationship between state IPT and unemployment rates (expressed as percentages) via a set of scatter plots covering the three years displayed for the earlier descriptive statistics in Table $1(2005,2010,2016)$ and for the full pooled sample. For purposes of direct comparison, the scales are identical across the four panels. The straight line in each panel is the least-squares linear fit between the two series, with observations weighted by state employment counts.

For each panel in Figure 3, we highlight four specific states: Alabama, California, Hawaii, and Nevada (identified by standard state abbreviations). These were chosen because they illustrate key patterns in the data, not because they fully summarize the relationship between IPT and unemployment across states and over time. That complete relationship is reflected in the fitted lines and will be explored further via the regression analyses in the next section. For readers interested in other states, however, we also provide a version with complete state labeling, in Appendix B (Figure B2). ${ }^{21}$

The scatter plots of IPT and unemployment rates in Figure 3 are relatively tight in the expansion years of 2005 and 2016 but much wider in 2010 when the labor market reached a trough. Consistent with the counter-cyclicality at the aggregate level illustrated in Figures 1 and

\footnotetext{
${ }^{21}$ In the appendix figure, the scales are different across the four panels, enabling visual identification of all state labels.
} 
2 (Section II), in all cases the fitted lines show a positive relationship between the unemployment and IPT rates, i.e. counter-cyclicality in the IPT rate. This relationship is relatively consistent in the cross-section: the slope of the fitted line increased somewhat between 2005 and 2010 and then was little changed in 2016.

This cross-state relationship between IPT and unemployment is not precise, however, with substantial deviations from the fitted lines evident. The four highlighted states are informative in this regard. Consistent with its low employment shares for key industries with high rates of part-time work, such as leisure and hospitality, Alabama has a low IPT rate relative to its unemployment rate in all years. The opposite is the case for California, Hawaii, and Nevada. The economies of the latter two states are heavily dependent on travel and tourism, especially Nevada, and hence have much higher shares of leisure and hospitality employment than any other state. Yet Nevada is less of an outlier with regard to high IPT rates than is Hawaii. This illustrates the importance of idiosyncratic state factors, such as Hawaii's longstanding employer health insurance mandate, which has been found to increase part-time employment in that state (Buchmueller, DiNardo, and Valletta 2011).

Because our subsequent regression analyses focus on changes over time, Figure B3 in Appendix B shows the IPT/unemployment scatter plots in change form, for three periods: the cyclical downturn from 2006 to 2010, the recovery from 2010 to 2016, and the complete period of 2006-16. Once again a strong countercyclical relationship is evident. In addition, the movements over time for the four highlighted states largely reflect their cross-section relationship, with an especially large cyclical swing in IPT in Hawaii, modest changes in Alabama, and a large increase in IPT work in Nevada over the entire sample frame (relative to the change in its unemployment rate). For additional details, Figure B4 shows the time-series of 
the IPT and unemployment rates for the four highlighted states.

Our regression analyses in the next section take into account these cyclical relationships and related factors that help explain state-specific deviations. Figures 4 and 5 provide further information about the variation used in our estimation framework. Each figure shows the distribution across the 51 states of average values over the entire 2006-2016 timeframe and changes over the 2006-2010, 2010-2016, and 2006-2016 periods, for the IPT rate in Figure 4 and the unemployment rate in Figure 5. The histograms show wide variation across states in the average levels and changes over time in the IPT and unemployment rates, in the recession and recovery periods and also between the largely comparable expansion years of 2006 and 2016. Cyclical changes in state IPT rates ranged from about 0 to 6 percentage points, which is very large relative to period averages centered around 4 to 5 percent. The change over the entire period from 2006 to 2016 ranges from slightly less than zero to over 3 percentage points. The level and change in the unemployment rate displays similar wide variation, although the changes between 2006 and 2016 are centered around zero.

Figures B5-B7 provide additional information about the variation used in our regression models via similar histograms for the distribution of selected industry shares, selected demographic group population shares, and labor costs across states. For brevity, we display figures for two industries only, the wholesale industry and leisure and hospitality industry; they differ markedly in their rates of part-time employment and also their changing shares of total employment over our sample frame, with the wholesale share declining and the leisure and hospitality share rising. We also display two demographic groups of particular interest (age 1624 and 65 and over, with the two genders combined). The panels display the period averages and the change from 2006 to 2016 . Figure B5 generally shows substantial dispersion in period 
averages and changes for the selected industry shares. The distribution of the average leisure and hospitality share across states is relatively tight around 10 percent, but the change over our sample frame is quite disperse, with a uniform distribution centered around 1 percentage point and ranging from 0 to 2 percentage points. Substantial dispersion in levels and changes is also evident for the demographic groups and labor costs in Figures B6 and B7.

\section{B. Regression Framework and Results}

The descriptive analyses of the state data suggest that cyclical conditions plus other statespecific market factors, both observed and unobserved, will affect changes in IPT at the state level. We account for such observed and unobserved state factors in our estimation framework

We estimate regressions of the following broad form using the state panel data:

$$
I P T_{s t}=\alpha+f\left(U_{s t}\right) \beta+X_{s t} \gamma+\varphi_{s}+\delta_{t}+\epsilon_{s t}
$$

where $s$ and $t$ index state and time (year). Because the dependent variable, the IPT rate, is measured as a fraction and takes values close to zero but bounded above it, we use the fractional regression methods developed in Papke and Wooldridge (2008). ${ }^{22}$ Observations are weighted by each state's average employment over the sample period, and the standard errors are clustered by state.

The parameters $\beta$ and $\gamma$ represent vectors of coefficients to be estimated, to capture the effects of the variable sets $f\left(U_{s t}\right)$ and $X_{s t}$ described below. Reported estimates in all cases are average marginal effects reflecting the impact of a unit change in each variable on the fraction of

\footnotetext{
${ }^{22}$ The estimator is available via the "fracreg" procedure starting with Stata Version 14. We use the logit functional form. Compared with our reported results, estimation based on a linear model generates a poor fit, especially for the cyclical component of the IPT rate.
} 
measured IPT in the state, with other explanatory variables held at their mean values.

Equation 1 specifies the cyclical component of variation in IPT as a flexible function of the state unemployment rate, $f\left(U_{s t}\right)$. Given the importance of cyclical variation for the overall differences in IPT across states and over time, we explore alternative specifications of the cyclical component below, using indicators beyond the unemployment rate. With the cyclical component pinned down, we then explore the effects of the variables in the vector $X_{s t}$ These are time-varying characteristics of state labor markets that are relevant for the determination of IPT employment, in particular the industry share, labor cost, and demographic categories discussed in the preceding sub-section. ${ }^{23,24}$

The regression models also include a complete set of state effects $\left(\varphi_{s}\right)$. The state fixed effects account for the influence of unmeasured time-invariant characteristics of state labor markets that may distort the estimated relationship between the IPT rate and the explanatory factors. The possible importance of such factors was suggested by the discussion in the preceding sub-section. The state effects are highly statistically significant in all specifications. ${ }^{25}$

\footnotetext{
${ }^{23}$ The mining and logging sectors are very small and for several states are not separately distinguished from the construction sector in the state payroll employment data. For consistency, we incorporate mining and logging employment into the construction sector for all states.

${ }^{24}$ In preliminary analyses, we incorporated data on health benefit costs, available at the state level from 2006 forward (excluding 2007) from the Medical Expenditure Panel Survey (MEPS, produced by the Agency for Healthcare Research and Quality). These measures had essentially no effect on the incidence of part-time work or the contribution of other explanatory factors in our empirical models restricted to the available time period. We therefore chose to exclude this factor from the analyses and use the longer timeframe enabled by the availability of the other variables. Health benefit costs do not vary with hours worked and as such are quasi-fixed (Lettau and Buchmueller 1999; Euwals and Hogerbrugge 2006; Dolfin 2006). While this will tend to increase employer costs associated with part-time labor, the resulting shift away from part-time labor will be offset to some degree by employers' ability to exclude part-time workers from health benefit plans or offer them lower quality plans. These conflicting influences may explain the limited effects of health insurance costs in our preliminary analyses.

${ }^{25}$ The point estimates and measures of statistical precision are nearly identical when the models are instead estimated using a logistic transformation of the dependent variable and a formal fixed-effects estimator. A conventional Hausman test strongly rejects a random effects specification in this alternative framework. We use the Papke-Wooldridge estimator with explicit state effects for computational
} 
In these regressions, the coefficients on the explanatory variables reflect the effects of changes in the directly measured factors within states over time. The vector of year indicators $\left(\delta_{t}\right)$ captures the remaining unexplained variation in IPT over time, attributable to unmeasured time-varying cyclical or other market determinants. These are a key focus of our analysis below, as we seek to explain them via the identifiable determinants of IPT discussed earlier.

We first focus on a proper specification for the cyclical component, with the observed state effects omitted (but state dummies included in all cases). As noted, the unemployment rate is most commonly used as the key indicator of cyclical conditions in national and state labor markets. Since the Great Recession, however, the sharp decline and continued low level of the employment-to-population ratio (EPOP) has raised the possibility that it may be an important alternative or supplemental measure of cyclical conditions in the national and state labor markets (see e.g. Bitler and Hoynes 2016). We therefore explore its role below. We also examine the potential impact of the broadest measure of state economic activity, real GDP (measured as an annual percentage change), which may account for features of the economic downturn not captured by the labor market variables.

Table 2 displays the regression results for this exploration of cyclical changes in IPT. In the first column, only the unemployment rate and the year dummies are included as explanatory variables beyond the state dummies. The strong cyclical component in the IPT rate is reflected in the large and precisely estimated marginal effect of the unemployment rate. It shows that the IPT rate increases by about 0.4 percentage points for a 1 percentage point increase in the unemployment rate. However, the estimated year effects indicate that the IPT rate increased

convenience with respect to the calculation of marginal effects in this section and the decomposition in Section VI. 
substantially more during the Great Recession and its aftermath than can be explained by changes in the unemployment rate. The reported marginal effects for the year dummies are directly interpreted as percentage point effects on the dependent IPT variable. They indicate a sharp upward drift in the IPT rate during the recession and recovery, peaking at 1.7 percentage points in 2013-14 and declining to 1.3 percentage points as of 2016. Although the unemployment rate alone explains much of the movement over time in the IPT rate, the year effects are meaningful relative to the typical IPT rate in the range of 3 to 7 percent.

The additional columns of Table 2 explore the specification of the cyclical effect. We add a quadratic term in the unemployment rate in column 2. This reduces the unexplained year effects, especially during the recession and early recovery years (2009 through 2013). The coefficient on the quadratic term is negative, suggesting that this specification more accurately captures cyclical movements in the IPT rate via nonlinear effects of very high and very low unemployment rates. ${ }^{26}$ In column 3, substitution of EPOP for the unemployment rate substantially reduces the accuracy of the cyclical component, with a sharp increase in the year effects evident during the recession. Supplementing the column 2 quadratic unemployment specification with EPOP (column 4) or the change in real GDP (column 5) does not further reduce the unexplained year effects. ${ }^{27}$

The Table 2 results indicate that cyclical variation in the IPT rate is well explained by a quadratic specification in the unemployment rate. We therefore use this specification (column 2) for the subsequent regressions that include additional state explanatory factors. Although cyclical

\footnotetext{
${ }^{26}$ Inclusion of additional higher order terms in the unemployment rate does not produce any further reduction in the year effects or improvement in overall fit.

${ }^{27}$ In the column 3 specification with EPOP, the unexplained year effects in 2014 through 2016 are smaller than in the other columns. This differential disappears when we include the state market factors in the model, in Table 4 (see footnote 31 ).
} 
variation accounts for most of the changes in IPT over our sample frame, even well into the economic recovery in 2016, the typical state IPT rate was more than a percentage point above the level expected based on cyclical variation only (specifically, 1.2 percentage points, the marginal effect of the 2016 year dummy in column 2).

Table 3 presents results from specifications that include observable structural characteristics of state labor markets that are likely to affect the relative demand and supply for IPT employment ( $X_{s t}$ in equation 1). Importantly, inclusion of the explanatory market factors greatly attenuates the otherwise unexplained increase in state IPT rates over time. The estimated year effects since the Great Recession are much smaller in column 1 of this table than in the baseline cyclical specification from column 2 in Table 2. Meaningful residual cyclical effects are reflected in the statistically significant coefficients on the year dummies in the recession and early recovery period (2008 through 2011). However, the year effects in column 1 of Table 3 decline steadily from about 1 percentage point in 2009, becoming statistically insignificant in 2012 and falling to slight negative values in 2015-2016.

Examination of the coefficients on the state market factors-labor costs, industry shares, and demographic group shares - in column 1 of Table 3 illustrates the explicit sources of time variation at the state level that largely eliminate the unexplained year effects from Table 2 . The key factor is variation in industry shares, based on the size and statistical precision of the estimates. ${ }^{28}$ For a few industries with high incidence of IPT and part-time work in general, such as leisure and hospitality and other services, the positive coefficients indicate that increases in

\footnotetext{
${ }^{28}$ For now, we focus on coefficients that attain conventional levels of statistical significance (generally $5 \%$ confidence or better). Section VI provides a formal decomposition that accounts for all factor contributions.
} 
their employment shares tend to increase the IPT rate, as expected. ${ }^{29}$ The converse is true for the wholesale trade sector, also as expected: it has a low incidence of IPT work, and the negative coefficient indicates that declines in this sector's employment share tend to increase the IPT rate.

It may seem surprising that for retail trade, which like leisure and hospitality also has a high incidence of IPT and part-time work in general, the coefficient on its share is small and statistically insignificant. This likely reflects offsetting effects from the pure composition component and the within-industry component: the retail employment share has been declining, likely prompting increased employer reliance on IPT work as a means to reduce work hours in general. Similar considerations likely explain the otherwise counterintuitive coefficients for the construction, transportation/communications/utilities, and education and health services sectors.

Estimates for the labor cost and demographic factors are small and statistically insignificant, although with expected signs in several instances. Based on the point estimates, states with a higher median wage tend to have a slightly higher incidence of IPT. ${ }^{30}$ States with a higher population share of younger working-age individuals and those age 65 and over tend to have lower IPT rates, consistent with the high incidence of VPT among these groups helping to meet employer needs for part-time labor.

The remaining columns of Table 3 explore alternative specifications of the state market components. Column 2 replaces the population shares with labor force shares (age 16 and over). The broad patterns in the results are little affected, but the population shares have greater explanatory power than the labor force shares. Substitution of occupation categories for industry

\footnotetext{
${ }^{29}$ IPT rates and shares by industry and other groups are provided in Table 1.

${ }^{30}$ The positive effect of the median wage on IPT suggests that this relationship reflects the effects of employer labor costs rather than more general labor demand influences. The latter would tend to increase wages and also reduce IPT work by inducing employers to increase hours worked.
} 
categories also has little impact on the year effects (compared with columns 1 and 2). However, the pattern in the occupation coefficients is largely uninformative, with the only significant effect coming from the office and administrative support category. Moreover, Column 4 shows that including occupation along with industry has very little impact on the estimated industry share effects, reinforcing our confidence that the industry effects account for the key sectoral developments that determine IPT. Finally, column 5 substitutes the $25^{\text {th }}$ percentile real hourly wage for the median, to account for possibly large IPT effects at lower wage percentiles. The coefficient on this variable is essentially zero and other results are largely unaffected.

On balance, the comparisons in Table 3 indicate that the alternatives considered do not improve upon our baseline model with industry shares, population shares, and the median and minimum wage measures. We therefore focus on this preferred specification of the state market factors in the remainder of the paper. ${ }^{31}$

\section{Regression Analyses using CPS Individual Data}

\section{A. Assessing IPT and VPT}

We further explore the determinants of part-time work using regressions that rely on the CPS individual microdata described in Section II. This provides a check on the state panel specification and enables more robust tests of the state cyclical and market effects, with individual characteristics explicitly introduced as controls. In addition, because we have direct information on voluntary as well as involuntary part-time work in the CPS data, we are able to compare and contrast their determinants.

31 Substituting or supplementing the unemployment quadratic with EPOP also has very little impact on the main results (time effects) in models with complete state factors. 
Our analysis of the CPS individual data is based on multinomial logit regressions. In particular, we estimate the determinants of IPT and VPT employment based on the following equation (with full-time work as the omitted category):

$$
\operatorname{Pr}\left(P T_{i s t}=j\right)=\alpha_{j}+f\left(U_{s t}\right) \beta_{j}+X_{s t} \gamma_{j}+Z_{i s t} \lambda_{j}+\varphi_{s j}+\delta_{t j}+\mu_{i s t j}
$$

for $j=I P T, V P T$

Individuals are indexed by $i$, with state of residence $s$ and observation year $t$. This equation is similar to equation 1 , estimated using the state panel data in the preceding sub-section (we use the same symbols for convenience). However, our individual data enable incorporation of individual controls, denoted $Z$, with estimated coefficients $\lambda$. Although our descriptive analyses in Section II demonstrated that individual composition effects do not meaningfully affect IPT changes over time, we include a detailed set of individual controls due to their possible interaction with the state cyclical and market effects but do not report their estimated effects. ${ }^{32}$ As with the state panel analyses, the coefficients are reported as average marginal effects, and the standard errors are clustered by state.

The results are listed in Table 4. We provide four different specifications, numbered 1-4, with the estimates for the IPT and VPT components labeled as "a" and "b" respectively. Similar to column 1 of Table 2, model 1 includes only the state unemployment rate and the year

\footnotetext{
${ }^{32}$ Specifically, we incorporate the effects of seven age categories by gender and marital status (28 total categories), five educational attainment categories, five race/ethnic categories, and the major industry and major occupation categories listed in Table 1 (less an omitted category in each case). The full set of controls is less detailed than that used for the reweighting analysis in Section II-B, to keep the computational burden manageable.
} 
effects. ${ }^{33}$ Relative to that specification, and in cumulative sequence, model 2 incorporates the individual controls, model 3 incorporates the measured state market factors, and model 4 incorporates unmeasured state effects (i.e., a complete set of state indicator variables). The specification from model 4 is most directly comparable to our preferred specification for the state panel analysis (column 1 of Table 3).

The results for the most basic specification, model 1, show the expected countercyclicality in the IPT rate and modest pro-cyclicality in the VPT rate (the positive and negative coefficients on the unemployment rate in columns 1a and 1b, respectively). As expected, the IPT results in column 1a of Table 4 also show the same strong upward drift over time as the state panel results in column 2 of Table 2 (due to their similar specifications except for the inclusion of state dummies in Table 2). Adding individual controls (column 2a) strengthens the measured counter-cyclicality for the IPT rate and also its upward drift over time, suggesting that composition effects associated with differing state business cycle conditions are important contributors to variation in IPT employment. By contrast, the inclusion of individual controls in column $2 \mathrm{~b}$ causes the unemployment rate coefficients to become statistically insignificant, eliminating pro-cyclicality in the VPT rate (a result that is maintained in subsequent columns).

The key models add state market effects (model 3) and explicit state dummies (model 4). The inclusion of state dummies is important for accurate estimation of the effects of the observable state factors, with substantial differences in the estimated effects for these factors between models 3 and $4 .{ }^{34} \mathrm{We}$ focus first on the results for the IPT component (columns $3 \mathrm{a}$ and

\footnotetext{
${ }^{33}$ Although the model includes dummies for all years (except the omitted category of 2006), the table only shows those from 2007 forward due to space considerations.

${ }^{34}$ Most prominently, the labor cost and selected demographic group effects are statistically meaningful in the absence of state dummies (model 3). This indicates substantial cross-section effects on the IPT and
} 
4a). Inclusion of the state market effects largely eliminates the upward drift in IPT work (column 3a), consistent with the state panel results in Table 3. With state dummies incorporated (column 4a of Table 4), the measured effects of the state market variables are roughly similar to those from our preferred specification using the state data (column 1 of Table 3). This reinforces the state panel results, since model 4 is essentially an individual level variant of that model. Some variation in the effects of industry shares is evident across the state panel and individual data settings, although the important effects of the employment shares of the construction, wholesale trade, and other services sectors are quite consistent.

Turning to voluntary part-time work, the effects of the various factors generally are different for VPT than for IPT, consistent with past work that found meaningful behavioral differences between these groups (Stratton 1996). Conditional on individual characteristics, industry shares have very limited impacts on the prevalence of VPT, which reinforces the interpretation of VPT as primarily reflecting worker supply rather than employer demand factors. A higher population share of individuals age 65 and over tends to increase the state VPT rate, consistent with the high prevalence of VPT work for this group.

Overall, the results from regressions using the individual CPS data (Table 4) confirm the key conclusions from the state panel analysis (Table 3). The absence of meaningful residual time effects in columns $3 \mathrm{a}$ and $4 \mathrm{a}$ in Table 3 indicates that changes in IPT work over time are largely explained by variation associated with overall labor market slack (state unemployment rates) and other state market factors. We provide a quantitative analysis of the contribution of these factors in section VI below.

VPT outcomes that are largely eliminated when state dummies are included and the remaining identifying variation is within states over time. 


\section{B. IPT and the Gig Economy (self-employment)}

We can also use the CPS data to further explore the possible interactions between IPT and informal gig economy jobs. As discussed in Section II, individuals working in such jobs are most likely identified as unincorporated self-employed workers (Abraham et al. 2017). However, the declining employment share of this group indicates that despite their high rate of IPT work, they are not a source of rising IPT employment in our data (discussed in Section II-B).

Despite these measurement challenges, a systematic relationship is likely to exist between informal gig work, which exhibits flexible and/or inconsistent hours, and part-time work schedules. Using original survey data, Bracha and Burke (2017) found that individuals who selfreport as IPT have a high probability of performing informal work. This finding suggests that a growing prevalence of IPT jobs may be a contributory factor for growth in the gig economy.

Table 5 explores this possibility. It reports logit regression results for the determinants of unincorporated self-employment in workers' primary job, multiple job holding, and unincorporated self-employment in a secondary job (for the sub-sample of multiple job holders). We use the same CPS individual data as in the multinomial logit analyses of IPT and VPT reported in the preceding sub-section (Table 4). The explanatory variables are largely the same as in Table 4, including the individual controls and state dummies. ${ }^{35}$ However, we exclude the state market factors and instead directly include the IPT rate as an explanatory variable. The reported coefficients are once again marginal effects on the probability of observing each of the three indicated outcomes (analyzed separately).

The results in Table 5 show that increases in the IPT fraction in a state are associated

\footnotetext{
${ }^{35}$ The individual controls exclude industry and occupation due to perfect predictions for multiple categories.
} 
with significantly higher rates of unincorporated self-employment on primary and secondary jobs, and higher rates of multiple job holding. By contrast, state unemployment rates have no meaningful impact on these outcomes, and the year effects show the downward drift over time that was also seen in Table 1. Despite the challenges of identifying gig work in the CPS, these results suggest that rising gig work in other data sources may partly be a response to the growing number of jobs that offer only part-time schedules.

\section{Accounting for IPT: Decomposition of Contributory Factors}

The regression analyses in the preceding sections identified cyclical and other marketbased factors that contributed to variation in IPT employment over our sample period of 2003 through 2016. In this section, we examine the quantitative contributions of the modeled factors to the movements in the aggregate IPT rate over time. We use the state panel data results from Section IV-B for this exercise and calculate how the average IPT rate varies over time based on variation in the explanatory variables measured at the state level. Our decomposition of the change in the average IPT rate between a base year 0 and year $t$ relies on the following equation:

$$
I P T_{t}-I P T_{0}=\sum_{s}\left[\Pi\left(\mathrm{T}_{s t}-\mathrm{T}_{s 0}\right) * e_{s}\right]
$$

In this equation, $T$ represents the complete set of time-varying explanatory factors from equation $1\left(U_{s t}, X_{s t}\right.$, and $\left.\delta_{t}\right)$; the elements of the vector $\Pi$ are their corresponding estimated marginal effects from our preferred specification reported in column 1 of Table $3 ; s$ indexes states; and $e_{s}$ is a weight equal to each state's share of total U.S. employment averaged over the 
sample frame. We calculate the contribution of each separate explanatory factor contained in $T .{ }^{36}$ Because the regression model for the fractional IPT outcome is nonlinear, the estimated marginal effects do not perfectly predict the change in the IPT, with the size of the discrepancy growing over time relative to the base year. We therefore applied a uniform rescaling to the contributions of each factor to ensure that the components sum to the observed change in the actual IPT rate. We use 2006 as our base year, hence the contributions of all explanatory factors in that year are identically zero.

Figure 6 and Table 6 summarize the main results from this analysis. The figure provides a visual display of the cyclical and structural contributions to movements in the IPT rate over time, with the complete set of structural market factors - industry, demographics, and labor costscombined into a single effect (with year effects excluded).${ }^{37}$ The directly measured cyclical component accounts for much of the increase in the IPT rate during the recession and immediate aftermath period of 2009-11. This component has declined along with state unemployment rates, and by 2016 it was down nearly to its pre-recession level. By contrast, after a slightly smaller rise during the recession, the contribution from the market factors has declined only slightly, keeping the aggregate IPT rate elevated by a bit more than a percentage point since 2010 .

Table 6 provides the exact numerical listing of the cyclical, structural, and year effects, for the period 2006 through 2016. The first column lists the change in the state average IPT rate from 2006, for each subsequent year. The other columns show the contributions from the cyclical component, the separate structural components (industry, demographics, and labor costs), and

\footnotetext{
${ }^{36}$ As is standard for regression decompositions, we include all estimated effects, even those that are not statistically significant.

${ }^{37}$ We exclude the year effects from the figure because it is unclear whether they reflect unmeasured cyclical or structural factors, hence the two broad components do not add to the total movement in the IPT series over the sample frame. Table 6 lists the precise quantitative contributions for the components.
} 
the remaining year effects, with the actual contributions and their share of the total change listed. The key contribution to the total structural effect comes from industry composition; it has stayed stable at about 1 to 1.1 percentage points from 2010 through 2016. Changing demographics made a modest net impact as well, keeping the IPT rate elevated by about 0.2 percentage points over this timeframe. The impact of labor costs is essentially zero, due to the small estimated marginal effects of the wage variables and limited changes in their values over time. As already noted in regard to the earlier regression results, the unexplained year effects are largely ignorable after 2013.

These results indicate that persistent changes in industry employment shares at the state level have made important contributions to the elevated level of IPT employment since the Great Recession. Table 7 probes these results further, by listing the contributions of key industries to the change in the IPT rate between 2006 and 2016. For readers interested in more details from the decomposition results, Appendix Table B1 lists the complete set of contributions from each individual explanatory variable, for the years 2010, 2013, and 2016.

Table 7 shows that the construction, wholesale, leisure and hospitality, and education and health services sectors each made a substantial contribution to the change in the IPT rate from 2006 to 2016, ranging from about 17 to 33 percent of the total change. This reflects the combination of their impact on the incidence of IPT (from the regression models) and their changing shares over the sample frame. As noted in regard to the regression results in Section IV-B, these results are as expected for the wholesale sector and the leisure and hospitality sector, based on the prevalence of IPT in these sectors and their changing employment shares from Table 1. The education and health services sector has low rates of IPT but high rates of VPT in Table 1, and a rising employment share. It is likely that the expansion of this sector in many 
states has increased demand for part-time workers and hence overall IPT work.

The results for the construction sector are somewhat anomalous. It tends to have high rates of IPT, so the direct effect of its declining employment share should be to reduce rather than increase IPT. The contribution of the construction sector may reflect the severity of the economic downturn in states most affected by the associated housing bust, with spillover effects to IPT employment in other sectors. Appendix Table B1 shows that its contribution has been diminishing over time, although this has been matched by rising contributions from other sectors, hence stability in the overall industry share effect.

Overall, the decomposition results show that despite the cyclical recovery from the Great Recession, the IPT rate has remained elevated by about a percentage point relative to prerecession levels. The persistent elevation of the IPT rate during the ongoing recovery from the Great Recession appears to be primarily attributable to persistent changes in demand for parttime work hours via changing industry employment patterns.

\section{Discussion and Conclusions}

We analyzed the determinants of involuntary part-time (IPT) employment, focusing on its unusually elevated levels as a share of total employment during and after the U.S. Great Recession of 2007-2009. Other recent research pointed to elevated levels of IPT during this period but did not reach definitive conclusions about the relative role of cyclical variation and other factors (e.g., Cajner et al. 2014; Canon et al. 2014). By contrast, our regression and decomposition methodology enables a relatively precise decomposition of contributory factors. Using state panel and individual CPS data for the period 2003 through 2016, we confirmed that the IPT rate depends heavily on cyclical variation in labor market conditions. However, we also 
identify slower moving market factors, reflected mainly in industry employment shares, which account for ongoing elevation in the IPT rate despite the cyclical recovery in the labor market. These market or structural factors account for about a percentage point or more of the elevated IPT share of total employment through 2016, with very little change in their overall contribution since the recovery began in 2010. These results suggest that the incidence of IPT employment is likely to remain somewhat elevated in the future as well.

As we noted earlier, similar patterns in IPT and part-time work more generally have been observed for other countries, suggesting that the determinants reflect broad labor market developments rather than institutional specifics. For example, the analysis of Borowczyk-Martins and Lalé (2017) uncovered shared patterns in labor market flows that contributed to recent elevation in IPT work in the United States and the United Kingdom. Additional international comparisons could prove quite informative with respect to the structural determinants of IPT. In particular, assessing the role of shared market factors will help shed light on the possible role of institutional specifics such as the ACA employer mandate in the United States, on which the direct evidence currently is mixed. We also uncovered suggestive evidence of links between rising IPT and work in the informal gig economy, despite the poor measurement of the latter in CPS data (Abraham et al. 2017). Further investigation using data sources that provide more precise and accurate information on informal gig work, such as linked tax data or original surveys, may prove useful to shed further light on such links.

Our framework and findings suggest other avenues for future work as well. We focused on recent empirical patterns in involuntary part-time work, discussing a market demand and supply framework in broad conceptual terms to guide our empirical analyses. More formal modeling of the demand and supply sides of the market for part-time work, and its general 
equilibrium properties, could be quite valuable for refining these findings. The wage effects of such changes are of particular interest and perhaps could be identified by focusing on industries with high incidence of part-time work, such as the retail and hospitality sectors. Accounting for the frictions that divide part-time workers into involuntary and voluntary groups is an especially interesting challenge for estimation of changes in the part-time wage penalty and may have important implication for movements in aggregate wages as well (as in Daly and Hobijn 2016). 


\section{References}

Abhayaratna, Joanna, Les Andrews, Hudan Nuch, and Troy Podbury. 2008. "Part Time Employment: The Australian Experience." Australian Government Productivity Commission Staff Working Paper.

Abraham, Katharine G., John C. Haltiwanger, Kristin Sandusky, and James R. Spletzer. 2017. "Measuring the Gig Economy: Current Knowledge and Open Issues." Working paper, University of Maryland, March.

Baker, Scott R., Nicholas Bloom, and Steven J. Davis. 2016. "Measuring Economic Policy Uncertainty.” Quarterly Journal of Economics 131 (4, Nov.): 1593-1636.

Bell, David N.F., and David G. Blanchflower. 2014. "Commentary: Labour Market Slack in the UK.” National Institute Economic Review No. 229, August.

Bitler, Marianne, and Hilary Hoynes. 2016. "The More Things Change, the More They Stay the Same? The Safety Net and Poverty in the Great Recession." Journal of Labor Economics 34(1, part 2): S403-444.

Blanchflower, David G., and Andrew T. Levin. 2015. "Labor Market Slack and Monetary Policy.” NBER Working Paper 21094, April.

Borowczyk-Martins, Daniel, and Etienne Lalé. 2016. "The Rise of Part-time Employment." Working paper, Copenhagen Business School and University of Bristol, July.

Borowczyk-Martins, Daniel, and Etienne Lalé. 2017. "Employment Adjustment and Part-time Work: Lessons from the United States and the United Kingdom.” Working paper, Copenhagen Busines School and Université du Québec à Montréal, December.

Borowczyk-Martins, Daniel, and Etienne Lalé. 2018. "The Welfare Effects of Involuntary Parttime Work." Oxford Economic Papers 70(1, Jan.): 183-205

Bracha, Anat, and Mary A. Burke. 2017. "Who Counts as Employed? Informal Work, Employment Status, and Labor Market Slack.” Working Paper 17-18, Opportunity \& Inclusive Growth Institute, Federal Reserve Bank of Minneapolis. June.

Buchmueller, Thomas C, John DiNardo, and Robert G Valletta. 2011. "The Effect of an Employer Health Insurance Mandate on Health Insurance Coverage and the Demand for Labor: Evidence from Hawaii." American Economic Journal-Economic Policy 3(4): 2551.

Cajner, Tomaz, Dennis Mawhirter, Christopher Nekarda, and David Ratner. 2014. "Why Is Involuntary Part-Time Work Elevated?" In FEDS Notes: Board of Governors of the Federal Reserve System. 
Canon, Maria E, Marianna Kudlyak, Guannan Luo, and Marisa Reed. 2014. "Flows to and from Working Part Time for Economic Reasons and the Labor Market Aggregates During and after the 2007-09 Recession." Federal Reserve Bank of Richmond Economic Quarterly 100(2): 87-111.

Carrington, William J, Kristin McCue, and Brooks Pierce. 2002. "Nondiscrimination Rules and the Distribution of Fringe Benefits." Journal of Labor Economics 20(2): S5-S33.

Cassidy, Natasha, and Stephanie Parson. 2017. "The Rising Share of Part-time Employment." Reserve Bank of Australia Bulletin, September Quarter: 19-26.

Chang, Yongsung, Sun-Bin Kim, Kyooho Kwon, and Richard Rogerson. 2011. "Interpreting Labor Supply Regressions in a Model of Full- and Part-Time Work." American Economic Review 101(3): 476-81.

Daly, Mary C., and Bart Hobijn. 2014. "Downward Nominal Wage Rigidities Bend the Phillips Curve." Journal of Money, Credit, and Banking 46(S2): 51-93.

Daly, Mary C., and Bart Hobijn. 2016. "The Intensive and Extensive Margins of Real Wage Adjustment.” FRBSF Working Paper 2016-04, March.

Daly, Mary C., and Robert G. Valletta. 2006. "Inequality and Poverty in the United States: The Effects of Rising Dispersion of Men's Earnings and Changing Family Behavior." Economica 73(Feb.): 75-98

Dillender, Marcus, Carolyn J. Heinrich, and Susan N. Houseman. 2016. "Effects of the Affordable Care Act on Part-Time Employment: Early Evidence. Upjohn Institute Working Paper 16-258. Kalamazoo, MI.

DiNardo, John, Nicole M. Fortin, and Thomas Lemieux. 1996. "Labor Market Institutions and the Distribution of Wages, 1973-1992: A Semiparametric Approach.” Econometrica 64 (5): 1001-1044.

Dolfin, Sarah. 2006. "An Examination of Firms' Employment Costs." Applied Economics 38(8): 861-78.

Euwals, Rob, and Maurice Hogerbrugge. 2006. "Explaining the Growth of Part-Time Employment: Factors of Supply and Demand." Labour 20(3): 533-57.

Even, William E., and David A. Macpherson. 2017. "The Affordable Care Act and the Growth of Involuntary Part-Time Employment.” Working paper, Trinity University, August.

Fallick, Bruce. 1999. "Part-time work and industry growth." Monthly Labor Review, March 1999: 22-29.

Friesen, Jane. 1997. "The Dynamic Demand for Part-Time and Full-Time Labour." Economica 64 (Aug.): 495-507. 
Garrett, Bowen A., Robert Kaestner, and Anuj Gangopadhyaya. 2017. "Recent Evidence on the ACA and Employment: Has the ACA Been a Job Killer? 2016 Update." Report, The Urban Institute, February.

Golden, Lonnie. 2016. "Still falling short on hours and pay.” Report, Economic Policy Institute, Washington, DC. December 5.

Hirsch, Barry T. 2005. "Why Do Part-Time Workers Earn Less? The Role of Worker and Job Skills." Industrial \& Labor Relations Review 58(4): 525-51.

International Monetary Fund. 2017. "Seeking Sustainable Growth: Short-Term Recovery, LongTerm Challenges.” World Economic Outlook, October. Washington, DC.

Katz, Lawrence F., and Alan B. Krueger. 2016. "The Rise and Nature of Alternative Work Arrangements in the United States, 1995-2015." NBER Working Paper 22667, September; revised June 2017.

Leppel, Karen, and Suzanne Heller Clain. 1988. "The growth in involuntary part-time employment of men and women." Applied Economics 20: 1155-66.

Leppel, Karen, and Suzanne Heller Clain. 1993. "Determinants of Voluntary and Involuntary Part-Time Employment.” Eastern Economic Journal 19(1, Winter): 59-70.

Lettau, Michael K, and Thomas C. Buchmueller. 1999. "Comparing Benefit Costs for Full- and Part-Time Workers." Monthly Labor Review 122(3): 30-35.

Mathur, Aparna, Sita Nataraj Slavova, and Michael R. Strain. 2016. "Has the Affordable Care Act increased part-time employment?" Applied Economics Letters 23(3): 222-225.

Moriya, Asako S., Thomas M. Selden, and Kosali I. Simon. 2016. "Little Change Seen In PartTime Employment as a Result of the Affordable Care Act." Health Affairs 35(1): 119123.

Papke, Leslie E., and Jeffrey M. Wooldridge. 2008. "Panel data methods for fractional response variables with an application to test pass rates." Journal of Econometrics (145): 121-133.

Polivka, Anne, and Stephen Miller. 1998. "The CPS After the Redesign: Refocusing the Economic Lens.” In Labor Statistics Measurement Issues, eds. John Haltiwanger, Marilyn Manser, and Robert Topel. Chicago: University of Chicago Press, pp. 249-289.

Robertson, John, and Ellyn Terry. 2014. "Part-Time for Economic Reasons: A Cross-Industry Comparison” FRB Atlanta Macroblog, July 18.

Stratton, Leslie S. 1996. “Are 'Involuntary’ Part-Time Workers Indeed Involuntary?” Industrial and Labor Relations Review 49(3, April): 522-36.

Tilly, Chris. 1991. "Reasons for the Continuing Growth of Part-Time Employment." Monthly Labor Review 114(3): 10-18. 
Valletta, Robert G, and Leila Bengali. 2013. "What's Behind the Increase in Part-Time Work?" FRBSF Economic Letter 2013-24, August 26.

Valletta, Robert G, and Catherine van der List. 2015. "Involuntary Part-Time Work: Here to Stay?" FRBSF Economic Letter 2015-19, June 8.

Yellen, Janet. 2014. "Labor Market Dynamics and Monetary Policy.” Speech at the FRB Kansas City Economic Symposium, Jackson Hole, Wyoming, August 22. 


\section{Figure 1}

Part-time Work by Type (share of total employment), Jan. 1994-Dec. 2016

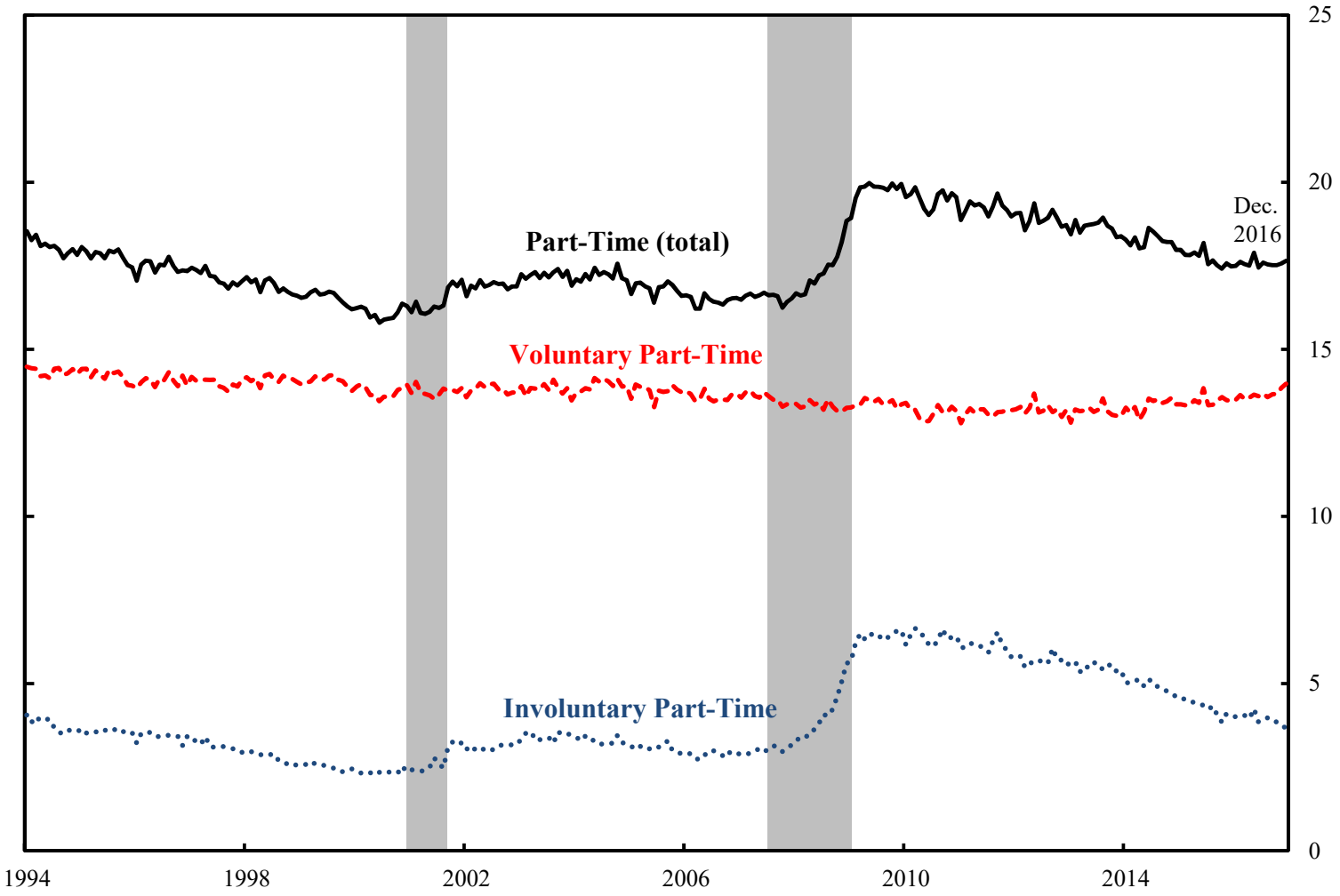

Source: BLS (seasonally adjusted data). Part-time rates expressed as a share of total civilian employment. Gray areas are recessions. 
Figure 2

Panel A

Involuntary Part-Time Rate vs. Unemployment Rate, Jan. 1994-Dec. 2016

Percent

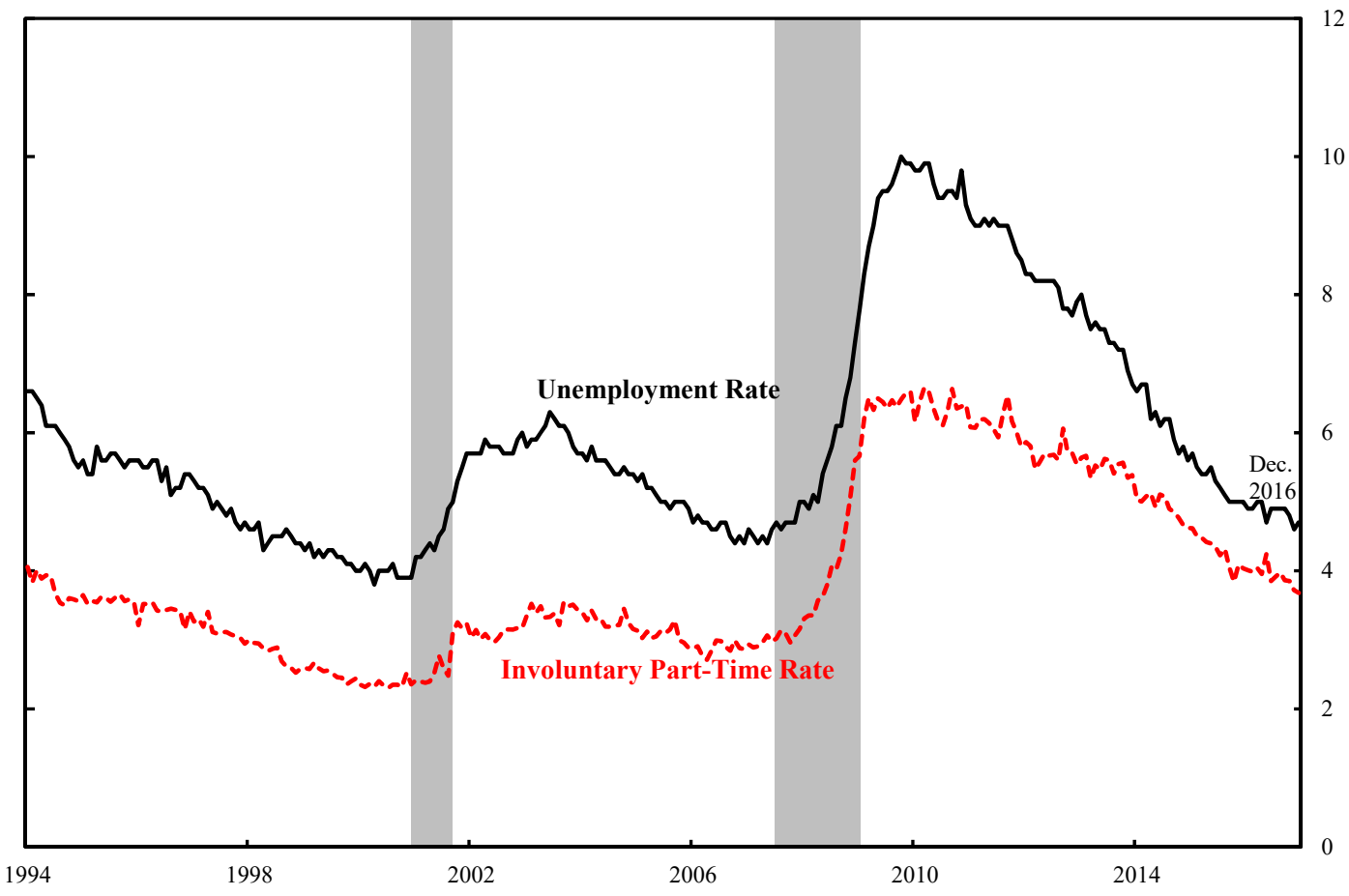

Source: BLS (seasonally adjusted data). Involuntary part-time rate expressed as a share of total civilian employment. Gray areas are recessions.

\section{Panel B}

Unemployment and Involuntary Part-Time (IPT) Components, Jan. 1994-Dec. $2016 \quad$ Percent

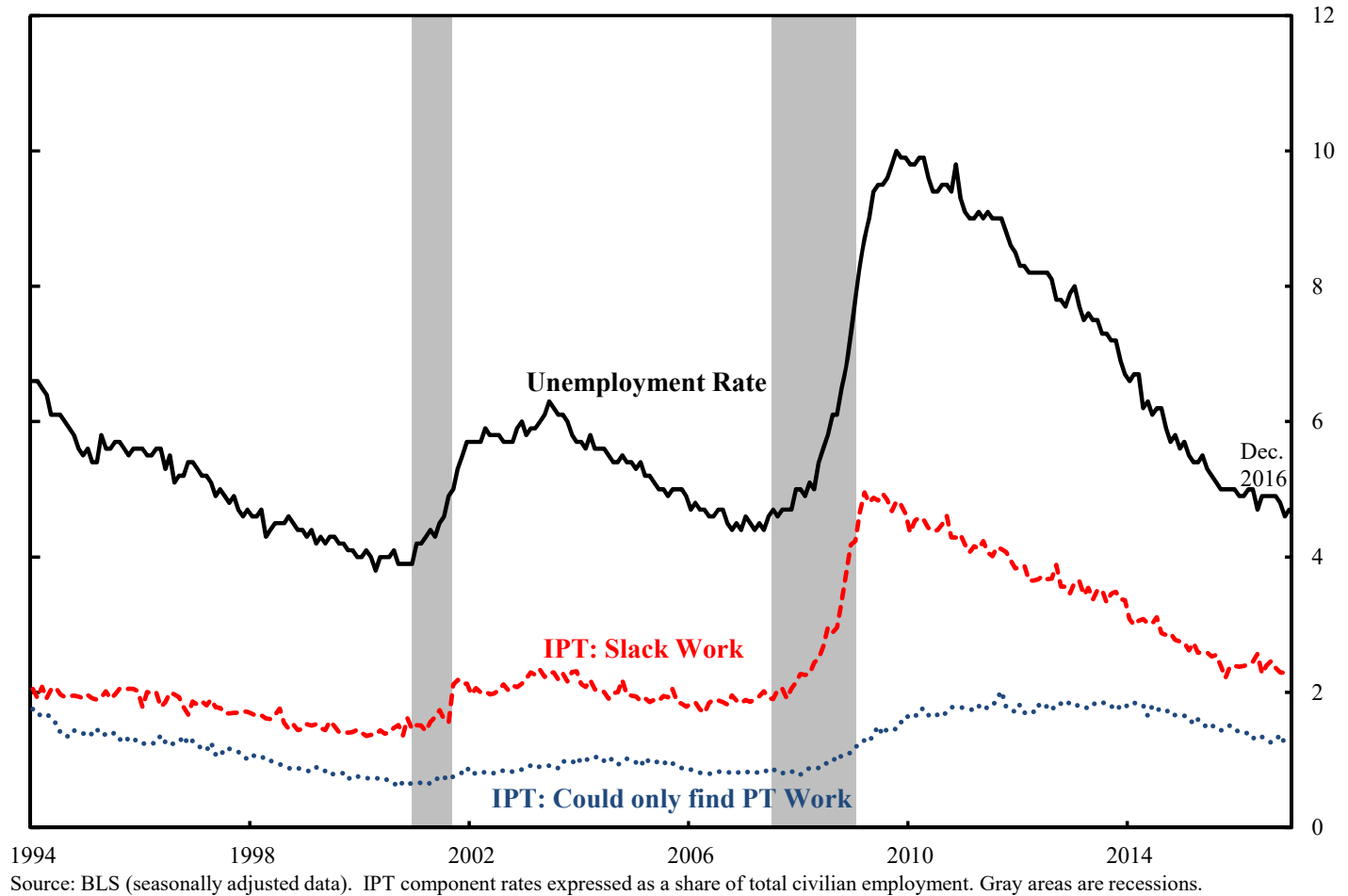




\section{Figure 3}

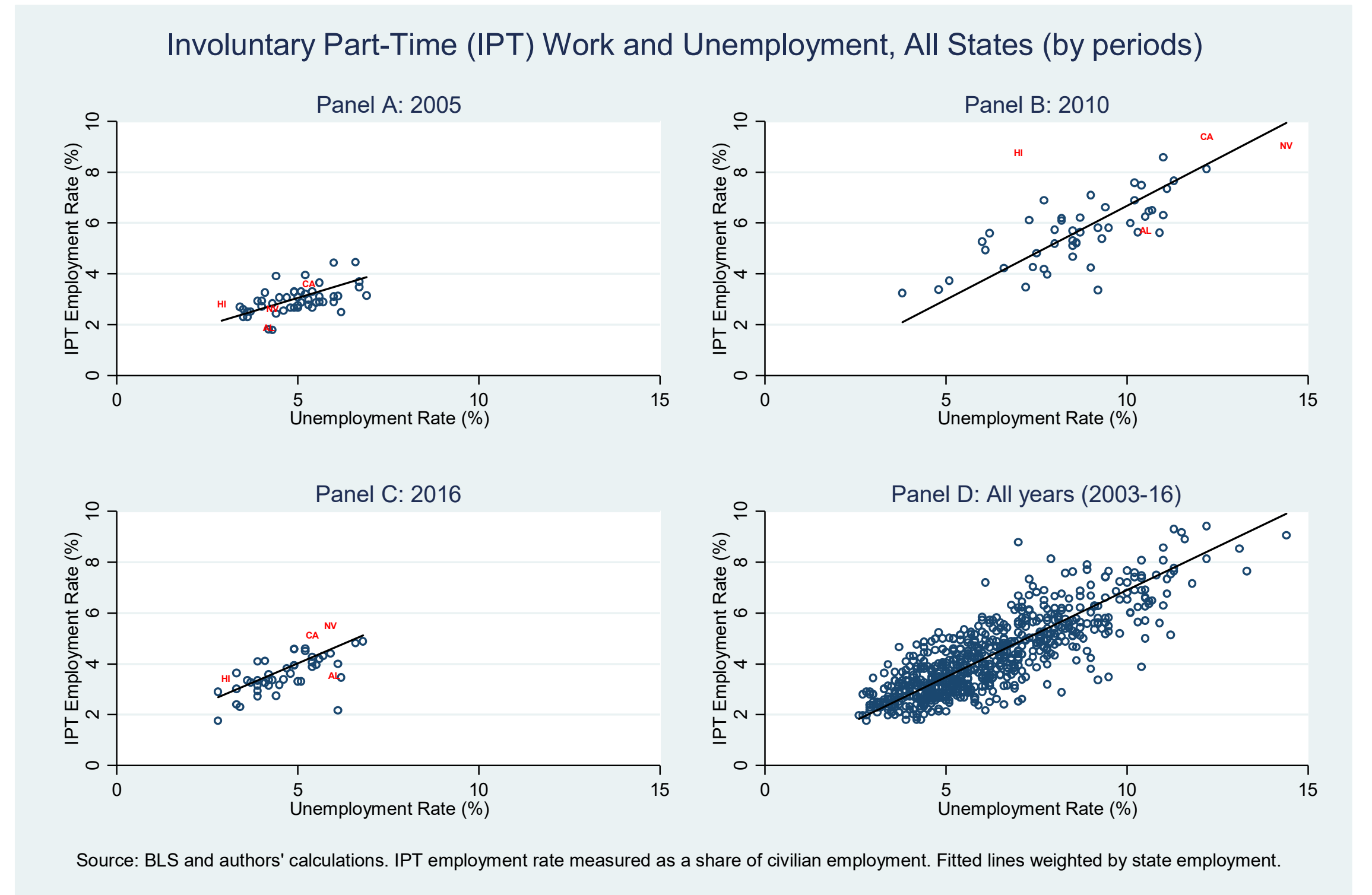




\section{Figure 4}

Distribution of IPT Employment Rates across States

Sub-period levels and changes
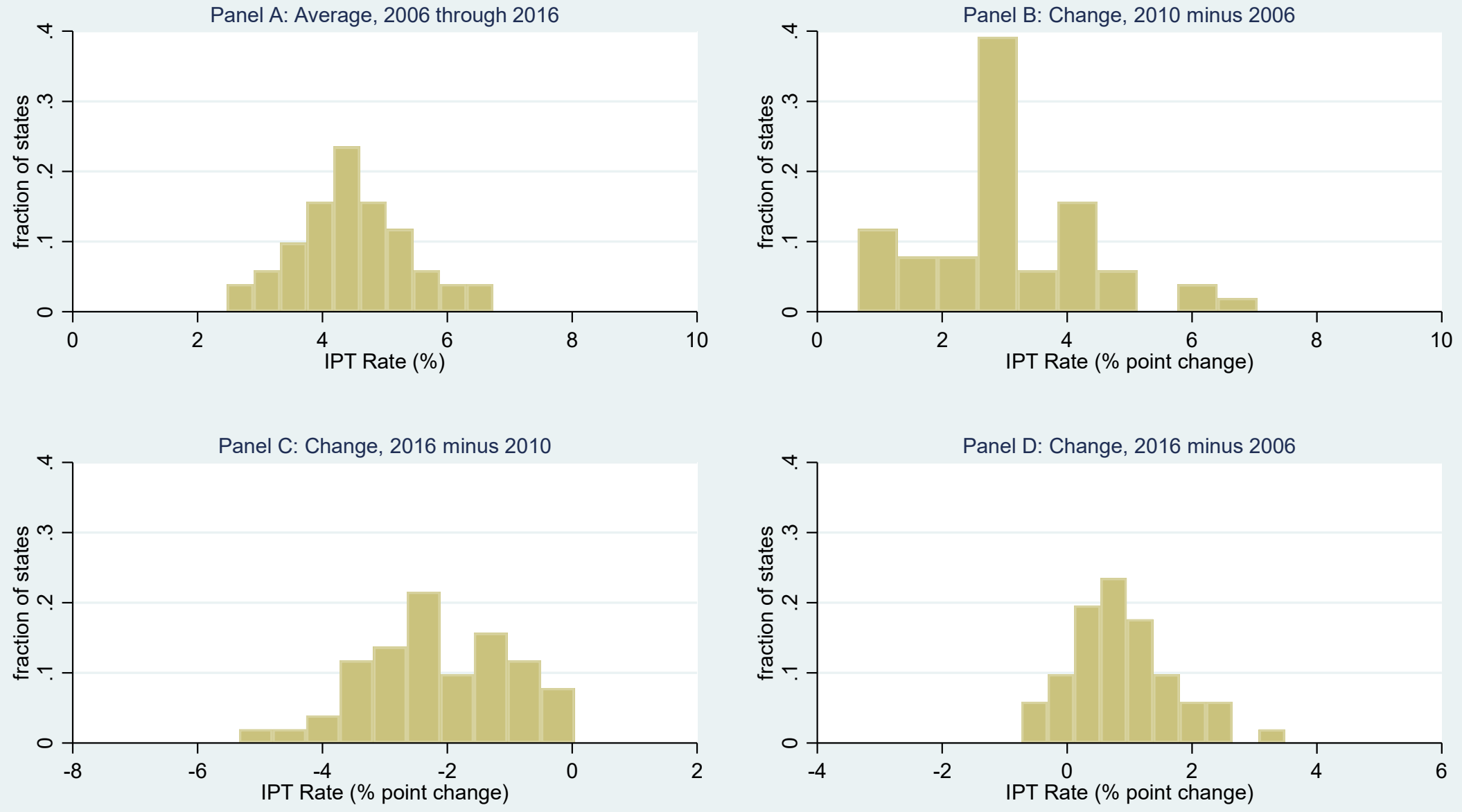

Source: BLS and authors' calculations. IPT employment rate measured as a share of civilian employment. 


\section{Figure 5}

\section{Distribution of Unemployment Rates across States}

\section{Sub-period levels and changes}
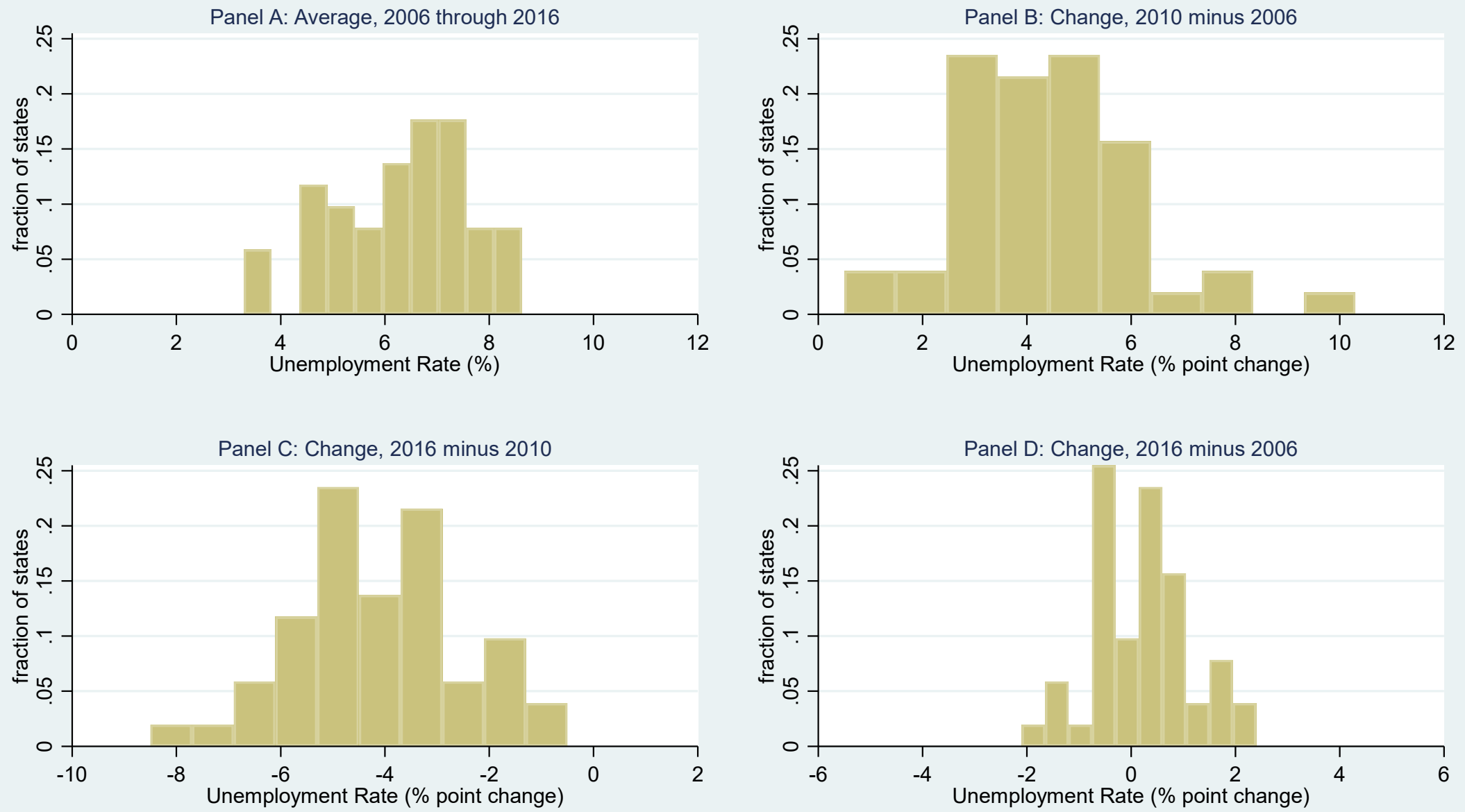

Source: BLS and authors' calculations. 


\section{Figure 6}

Involuntary Part-Time Employment (IPT), 2003-16

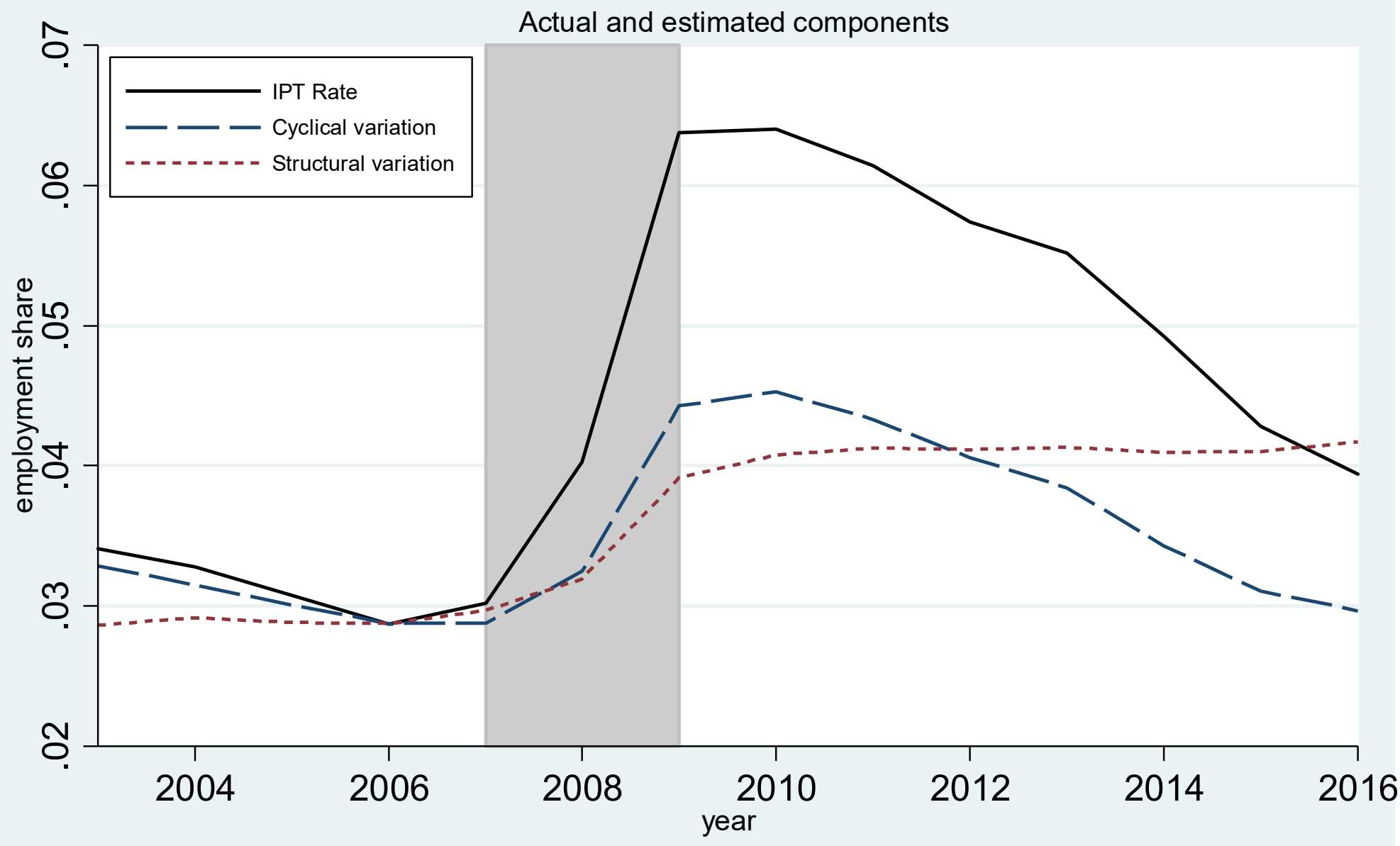

Note: Authors' calculations based on decomposition applied to regression results from column 1 of Table 3; components measured relative to 2006 (see text for details). Year effects excluded. Series are measured as shares of civilian employment. Gray area denotes recession (approximate). 
Table 1: Part-Time Work by Labor Market Group and Sector

(incidence by group) ${ }^{1}$

\begin{tabular}{|c|c|c|c|c|c|c|c|c|c|c|c|c|}
\hline & (1) & (2) & (3) & (4) & (5) & (6) & (7) & (8) & (9) & (10) & (11) & (12) \\
\hline & Involun & Part-ti & Norkers & Volunta & Part-Tin & Vorkers & Sum: I & $\begin{array}{l}\text { untary } \\
\text { Cime W }\end{array}$ & $\begin{array}{l}\text { luntary } \\
\text { rs }\end{array}$ & & $\begin{array}{l}\text { Memo: } \\
\text { yment }\end{array}$ & \\
\hline & 2005 & 2010 & 2016 & 2005 & 2010 & 2016 & 2005 & 2010 & 2016 & 2005 & 2010 & 2016 \\
\hline \multicolumn{13}{|l|}{ Individual Characteristics } \\
\hline All Workers & 0.032 & 0.066 & 0.041 & 0.143 & 0.136 & 0.142 & 0.175 & 0.203 & 0.182 & 1.000 & 1.000 & 1.000 \\
\hline \multicolumn{13}{|l|}{ Demographics: age by gender } \\
\hline All 16-24 & 0.058 & 0.117 & 0.075 & 0.353 & 0.357 & 0.367 & 0.411 & 0.474 & 0.442 & 0.143 & 0.125 & 0.127 \\
\hline Men 25-34 & 0.032 & 0.072 & 0.040 & 0.039 & 0.043 & 0.048 & 0.071 & 0.115 & 0.089 & 0.123 & 0.121 & 0.123 \\
\hline Women $25-34$ & 0.036 & 0.069 & 0.044 & 0.156 & 0.139 & 0.140 & 0.192 & 0.208 & 0.184 & 0.100 & 0.103 & 0.106 \\
\hline Men 35-54 & 0.023 & 0.053 & 0.029 & 0.025 & 0.025 & 0.029 & 0.048 & 0.078 & 0.058 & 0.251 & 0.240 & 0.225 \\
\hline Women $35-54$ & 0.029 & 0.061 & 0.039 & 0.156 & 0.144 & 0.143 & 0.185 & 0.205 & 0.181 & 0.227 & 0.220 & 0.201 \\
\hline All 55-64 & 0.025 & 0.053 & 0.034 & 0.138 & 0.126 & 0.122 & 0.163 & 0.179 & 0.156 & 0.125 & 0.151 & 0.165 \\
\hline All 65+ & 0.023 & 0.043 & 0.027 & 0.444 & 0.386 & 0.360 & 0.467 & 0.429 & 0.387 & 0.031 & 0.040 & 0.053 \\
\hline \multicolumn{13}{|c|}{ Demographics: marital status by gender (all ages) } \\
\hline Single man & 0.047 & 0.092 & 0.057 & 0.138 & 0.130 & 0.139 & 0.185 & 0.222 & 0.196 & 0.216 & 0.217 & 0.233 \\
\hline Single woman & 0.044 & 0.085 & 0.056 & 0.211 & 0.197 & 0.210 & 0.255 & 0.282 & 0.266 & 0.225 & 0.231 & 0.241 \\
\hline Married man & 0.019 & 0.046 & 0.023 & 0.045 & 0.047 & 0.050 & 0.063 & 0.093 & 0.073 & 0.312 & 0.303 & 0.292 \\
\hline Married woman & 0.025 & 0.051 & 0.030 & 0.212 & 0.195 & 0.189 & 0.237 & 0.246 & 0.219 & 0.246 & 0.249 & 0.234 \\
\hline \multicolumn{13}{|l|}{ Education Level } \\
\hline Less than High School & 0.065 & 0.138 & 0.076 & 0.239 & 0.212 & 0.250 & 0.305 & 0.350 & 0.326 & 0.115 & 0.093 & 0.083 \\
\hline High School & 0.038 & 0.085 & 0.057 & 0.120 & 0.117 & 0.128 & 0.159 & 0.202 & 0.185 & 0.300 & 0.283 & 0.262 \\
\hline Some College & 0.028 & 0.063 & 0.040 & 0.170 & 0.171 & 0.176 & 0.198 & 0.234 & 0.216 & 0.291 & 0.295 & 0.292 \\
\hline Bachelor's & 0.018 & 0.036 & 0.024 & 0.106 & 0.101 & 0.100 & 0.124 & 0.137 & 0.124 & 0.195 & 0.216 & 0.231 \\
\hline More than Bachelor's & 0.014 & 0.025 & 0.016 & 0.097 & 0.098 & 0.098 & 0.111 & 0.123 & 0.114 & 0.098 & 0.113 & 0.132 \\
\hline \multicolumn{13}{|l|}{ Race/ethnicity } \\
\hline White & 0.027 & 0.055 & 0.033 & 0.159 & 0.150 & 0.152 & 0.186 & 0.205 & 0.185 & 0.698 & 0.683 & 0.637 \\
\hline Black & 0.045 & 0.077 & 0.056 & 0.101 & 0.104 & 0.118 & 0.146 & 0.181 & 0.173 & 0.110 & 0.111 & 0.120 \\
\hline Hispanic & 0.050 & 0.116 & 0.061 & 0.103 & 0.101 & 0.124 & 0.153 & 0.217 & 0.185 & 0.125 & 0.137 & 0.152 \\
\hline Asian/Pacific Islander & 0.026 & 0.055 & 0.031 & 0.119 & 0.111 & 0.118 & 0.145 & 0.166 & 0.149 & 0.046 & 0.050 & 0.063 \\
\hline Other & 0.046 & 0.092 & 0.057 & 0.148 & 0.141 & 0.162 & 0.193 & 0.233 & 0.220 & 0.021 & 0.020 & 0.028 \\
\hline \multicolumn{13}{|l|}{ Self employment and multiple jobs } \\
\hline Self-employed (unincorporated) & 0.056 & 0.131 & 0.079 & 0.211 & 0.211 & 0.239 & 0.267 & 0.342 & 0.318 & 0.068 & 0.064 & 0.058 \\
\hline Multiple job holders & 0.024 & 0.046 & 0.033 & 0.107 & 0.099 & 0.109 & 0.131 & 0.146 & 0.142 & 0.053 & 0.050 & 0.050 \\
\hline Self-employed on second job ${ }^{3}$ & 0.023 & 0.045 & 0.029 & 0.076 & 0.082 & 0.096 & 0.099 & 0.127 & 0.126 & 0.224 & 0.199 & 0.183 \\
\hline
\end{tabular}


Table 1 (continued): Part-Time Work (incidence by group)

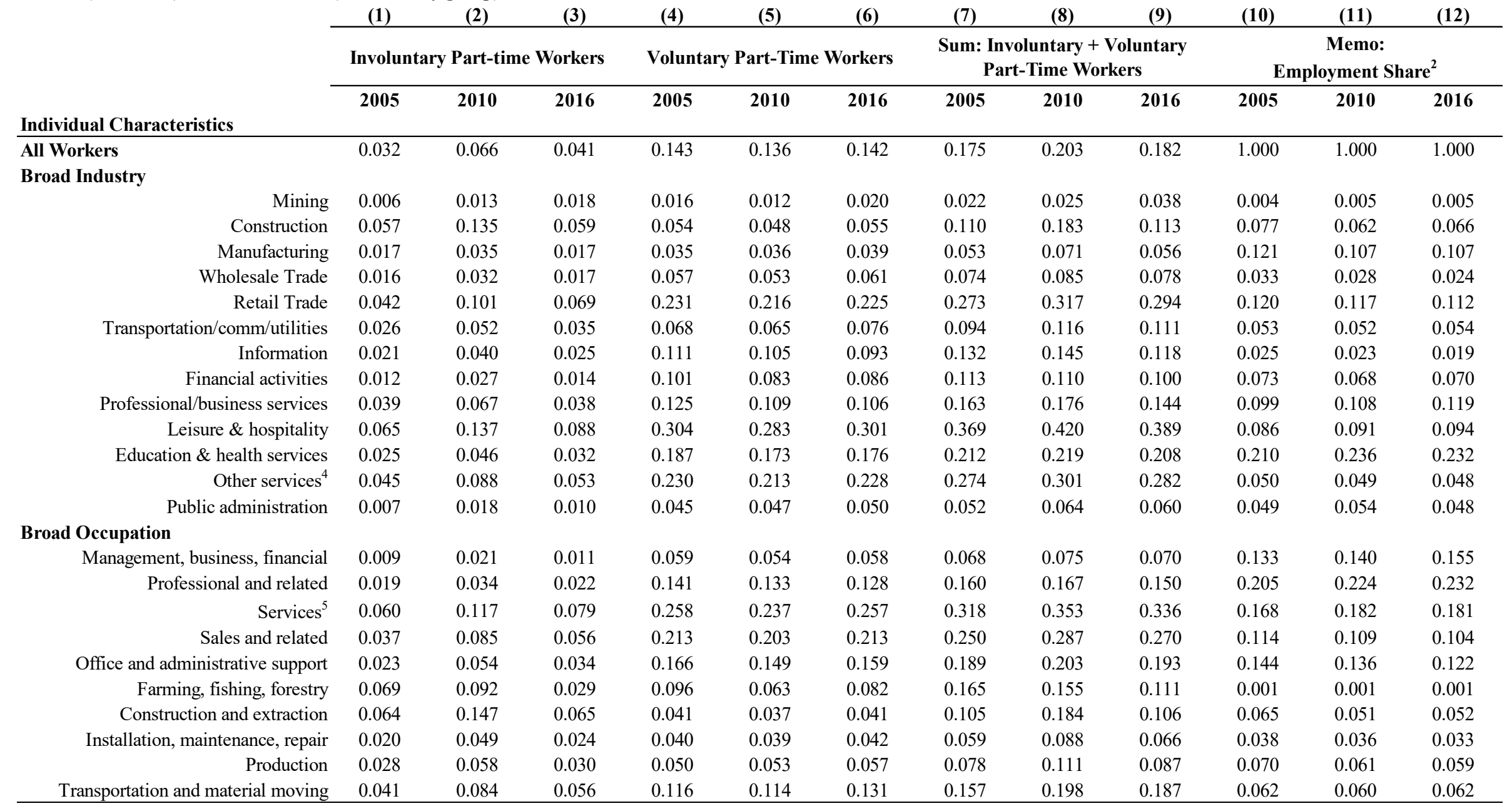

${ }^{1}$ Numbers in the first six columns represent the share of all employed individuals for the row category who are in the column category of part-time work (by year).

${ }^{2}$ Share of row group in total employment (part-time and full-time).

${ }^{3}$ Calculated for multiple job holders; data available for CPS outgoing rotation groups (quarter sample) only. Employment share measured as a fraction of multiple job holders.

${ }^{4}$ Includes repair/maintenance, personal services, and membership organizations.

${ }^{5}$ Includes healthcare support, protective, food preparation and serving, maintenance, and personal services.

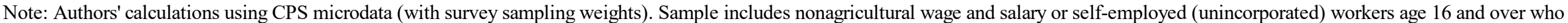
worked positive hours in the survey week and whose hours data were not allocated. 
Table 2: Involuntary Part-Time (IPT) Regression Results, 2003-2016: Cyclical Effects (dependent variable is IPT as fraction of state civilian employment; average marginal effects reported)

\begin{tabular}{|c|c|c|c|c|c|}
\hline $\begin{array}{l}\text { Variables } \\
\text { (by category) }\end{array}$ & (1) & (2) & (3) & (4) & (5) \\
\hline \multicolumn{6}{|l|}{ Cyclical } \\
\hline \multirow[t]{2}{*}{ Unemployment Rate (fraction) } & $0.413 * * *$ & $1.020^{* * *}$ & - & $1.026^{* * *}$ & $0.994 * * *$ \\
\hline & $(0.032)$ & $(0.115)$ & & $(0.109)$ & $(0.109)$ \\
\hline \multirow[t]{2}{*}{ (Unemp Rate Squared)*10 } & - & $-0.338 * * *$ & - & $-0.337 * * *$ & $-0.332 * * *$ \\
\hline & & $(0.066)$ & & $(0.067)$ & $(0.065)$ \\
\hline \multirow[t]{2}{*}{ Employment/population ratio (fraction) } & - & - & $-0.207 * * *$ & 0.013 & 0.011 \\
\hline & & & $(0.048)$ & $(0.030)$ & $(0.030)$ \\
\hline \multirow[t]{2}{*}{ Percentage Change GDP } & - & - & - & - & $-0.024 * * *$ \\
\hline & & & & & $(0.009)$ \\
\hline \multicolumn{6}{|l|}{$\underline{\text { Year (2006 omitted) }}$} \\
\hline \multirow[t]{2}{*}{2003} & $0.002 * *$ & $-0.002 *$ & $0.006 * * *$ & $-0.002 *$ & -0.001 \\
\hline & $(0.001)$ & $(0.001)$ & $(0.001)$ & $(0.001)$ & $(0.001)$ \\
\hline \multirow[t]{2}{*}{2004} & $0.002 * * *$ & -0.000 & $0.004 * * *$ & -0.000 & 0.000 \\
\hline & $(0.001)$ & $(0.001)$ & $(0.001)$ & $(0.001)$ & $(0.001)$ \\
\hline \multirow[t]{2}{*}{2005} & 0.001 & -0.000 & $0.002 * * *$ & -0.000 & 0.000 \\
\hline & $(0.001)$ & $(0.001)$ & $(0.001)$ & $(0.001)$ & $(0.001)$ \\
\hline \multirow[t]{2}{*}{2007} & $0.002 * *$ & $0.002 * * *$ & $0.002 *$ & $0.002 * * *$ & $0.002 * *$ \\
\hline & $(0.001)$ & $(0.001)$ & $(0.001)$ & $(0.001)$ & $(0.001)$ \\
\hline \multirow[t]{2}{*}{2008} & $0.010^{* * *}$ & $0.007 * * *$ & $0.013 * * *$ & $0.007 * * *$ & $0.006^{* * *}$ \\
\hline & $(0.001)$ & $(0.001)$ & $(0.002)$ & $(0.001)$ & $(0.001)$ \\
\hline \multirow[t]{2}{*}{2009} & $0.016^{* * *}$ & $0.010 * * *$ & $0.028 * * *$ & $0.011 * * *$ & $0.010^{* * *}$ \\
\hline & $(0.002)$ & $(0.002)$ & $(0.002)$ & $(0.002)$ & $(0.002)$ \\
\hline \multirow[t]{2}{*}{2010} & $0.014 * * *$ & $0.009^{* * *}$ & $0.026^{* * *}$ & $0.009 * * *$ & $0.010^{* * *}$ \\
\hline & $(0.002)$ & $(0.002)$ & $(0.002)$ & $(0.002)$ & $(0.002)$ \\
\hline \multirow[t]{2}{*}{2011} & $0.015^{* * *}$ & $0.010^{* * *}$ & $0.024 * * *$ & $0.010^{* * *}$ & $0.011^{* * *}$ \\
\hline & $(0.002)$ & $(0.002)$ & $(0.002)$ & $(0.002)$ & $(0.002)$ \\
\hline \multirow[t]{2}{*}{2012} & $0.016^{* * *}$ & $0.010^{* * *}$ & $0.021 * * *$ & $0.011 * * *$ & $0.011^{* * *}$ \\
\hline & $(0.002)$ & $(0.002)$ & $(0.002)$ & $(0.002)$ & $(0.002)$ \\
\hline \multirow[t]{2}{*}{2013} & $0.017^{* * *}$ & $0.012 * * *$ & $0.019 * * *$ & $0.012 * * *$ & $0.013 * * *$ \\
\hline & $(0.002)$ & $(0.002)$ & $(0.002)$ & $(0.002)$ & $(0.002)$ \\
\hline \multirow[t]{2}{*}{2014} & $0.017 * * *$ & $0.014^{* * *}$ & $0.015^{* * *}$ & $0.014 * * *$ & $0.014 * * *$ \\
\hline & $(0.001)$ & $(0.001)$ & $(0.002)$ & $(0.002)$ & $(0.002)$ \\
\hline \multirow[t]{2}{*}{2015} & $0.015^{* * *}$ & $0.013 * * *$ & $0.010 * * *$ & $0.013 * * *$ & $0.013 * * *$ \\
\hline & $(0.001)$ & $(0.001)$ & $(0.002)$ & $(0.002)$ & $(0.002)$ \\
\hline \multirow[t]{2}{*}{2016} & $0.013 * * *$ & $0.012 * * *$ & $0.007 * * *$ & $0.012 * * *$ & $0.012 * * *$ \\
\hline & $(0.001)$ & $(0.001)$ & $(0.002)$ & $(0.002)$ & $(0.002)$ \\
\hline State Dummies & Yes & Yes & Yes & Yes & Yes \\
\hline Pseudo $\mathrm{R}^{2}$ & 0.0151 & 0.0153 & 0.0147 & 0.0153 & 0.0153 \\
\hline $\mathrm{N}$ & 714 & 714 & 714 & 714 & 714 \\
\hline
\end{tabular}

$* * * \mathrm{p}<0.01, * * \mathrm{p}<0.05, * \mathrm{p}<0.10$

Notes: Standard errors in parentheses (clustered by state). Mean of state civilian employment used for regression weights. 
Table 3: Involuntary Part-Time (IPT) Regression Results, 2003-2016: with State Factors (dependent variable is IPT as fraction of state civilian employment; average marginal effects reported)

\begin{tabular}{|c|c|c|c|c|c|}
\hline $\begin{array}{l}\text { Variables } \\
\text { (by category) }\end{array}$ & $\begin{array}{c}\text { (1) } \\
\text { Baseline } \\
\text { specification (with } \\
\text { state market factors) }\end{array}$ & $\begin{array}{l}\text { (2) } \\
\text { (1) with labor } \\
\text { force rather than } \\
\text { pop shares }\end{array}$ & $\begin{array}{l}\text { (3) } \\
\text { (1) with } \\
\text { occupation } \\
\text { rather than } \\
\text { industry }\end{array}$ & $\begin{array}{c}\text { (4) } \\
\text { (1) with } \\
\text { occupation } \\
\text { added }\end{array}$ & $\begin{array}{l}\quad(5) \\
\text { (1) with } 25 \text { th } \\
\text { percentile wage } \\
\text { rather than } \\
\text { median }\end{array}$ \\
\hline \multicolumn{6}{|l|}{ Cyclical } \\
\hline Unemployment Rate (fraction) & $\begin{array}{l}0.632 * * * \\
(0.101)\end{array}$ & $\begin{array}{l}0.650^{* * *} \\
(0.098)\end{array}$ & $\begin{array}{l}0.913^{* * * *} \\
(0.093)\end{array}$ & $\begin{array}{l}0.611^{* * *} \\
(0.096)\end{array}$ & $\begin{array}{l}0.638^{* * * *} \\
(0.101)\end{array}$ \\
\hline (Unemp Rate Squared)*10 & $\begin{array}{l}-0.205^{* * *} \\
(0.058)\end{array}$ & $\begin{array}{l}-0.210^{* * *} \\
(0.056)\end{array}$ & $\begin{array}{l}-0.303^{* * *} \\
(0.054)\end{array}$ & $\begin{array}{l}-0.193 * * * \\
(0.055)\end{array}$ & $\begin{array}{l}-0.207 * * * \\
(0.058)\end{array}$ \\
\hline \multicolumn{6}{|l|}{$\underline{\text { Year (2006 omitted) }}$} \\
\hline 2003 & $\begin{array}{c}0.002 \\
(0.001)\end{array}$ & $\begin{array}{c}0.002 \\
(0.001)\end{array}$ & $\begin{array}{c}0.000 \\
(0.001)\end{array}$ & $\begin{array}{c}0.002 \\
(0.001)\end{array}$ & $\begin{array}{c}0.001 \\
(0.001)\end{array}$ \\
\hline 2004 & $\begin{array}{c}0.001 \\
(0.001)\end{array}$ & $\begin{array}{c}0.001 \\
(0.001)\end{array}$ & $\begin{array}{c}0.001 \\
(0.001)\end{array}$ & $\begin{array}{c}0.001 \\
(0.001)\end{array}$ & $\begin{array}{c}0.001 \\
(0.001)\end{array}$ \\
\hline 2005 & $\begin{array}{c}0.001 \\
(0.001)\end{array}$ & $\begin{array}{c}0.001 \\
(0.001)\end{array}$ & $\begin{array}{c}0.001 \\
(0.001)\end{array}$ & $\begin{array}{c}0.001 \\
(0.001)\end{array}$ & $\begin{array}{c}0.001 \\
(0.001)\end{array}$ \\
\hline 2007 & $\begin{array}{c}0.001 \\
(0.001)\end{array}$ & $\begin{array}{c}0.001 \\
(0.001)\end{array}$ & $\begin{array}{c}0.001 \\
(0.001)\end{array}$ & $\begin{array}{c}0.001 \\
(0.001)\end{array}$ & $\begin{array}{c}0.001 \\
(0.001)\end{array}$ \\
\hline 2008 & $\begin{array}{l}0.006^{* * *} \\
(0.001)\end{array}$ & $\begin{array}{l}0.006^{* * *} \\
(0.001)\end{array}$ & $\begin{array}{l}0.006^{* * * *} \\
(0.001)\end{array}$ & $\begin{array}{l}0.006 * * * \\
(0.001)\end{array}$ & $\begin{array}{l}0.006^{* * * *} \\
(0.001)\end{array}$ \\
\hline 2009 & $\begin{array}{l}0.009^{* * *} \\
(0.002)\end{array}$ & $\begin{array}{l}0.010^{* * *} \\
(0.002)\end{array}$ & $\begin{array}{l}0.009^{* * *} \\
(0.003)\end{array}$ & $\begin{array}{l}0.009^{* * *} \\
(0.002)\end{array}$ & $\begin{array}{l}0.010^{* * * *} \\
(0.002)\end{array}$ \\
\hline 2010 & $\begin{array}{l}0.007 * * \\
(0.003)\end{array}$ & $\begin{array}{l}0.007 * * * \\
(0.002)\end{array}$ & $\begin{array}{l}0.006^{* *} \\
(0.003)\end{array}$ & $\begin{array}{l}0.007 * * \\
(0.003)\end{array}$ & $\begin{array}{l}0.008^{* * * *} \\
(0.003)\end{array}$ \\
\hline 2011 & $\begin{array}{c}0.006^{*} \\
(0.003)\end{array}$ & $\begin{array}{l}0.006^{* *} \\
(0.002)\end{array}$ & $\begin{array}{c}0.005 \\
(0.004)\end{array}$ & $\begin{array}{c}0.006^{*} \\
(0.003)\end{array}$ & $\begin{array}{l}0.007 * * \\
(0.003)\end{array}$ \\
\hline 2012 & $\begin{array}{c}0.005 \\
(0.003)\end{array}$ & $\begin{array}{l}0.005^{* *} \\
(0.002)\end{array}$ & $\begin{array}{c}0.004 \\
(0.004)\end{array}$ & $\begin{array}{c}0.005 \\
(0.003)\end{array}$ & $\begin{array}{l}0.006^{* *} \\
(0.003)\end{array}$ \\
\hline 2013 & $\begin{array}{c}0.005 \\
(0.004)\end{array}$ & $\begin{array}{c}0.004 * \\
(0.003)\end{array}$ & $\begin{array}{c}0.004 \\
(0.004)\end{array}$ & $\begin{array}{c}0.004 \\
(0.004)\end{array}$ & $\begin{array}{c}0.006^{*} \\
(0.003)\end{array}$ \\
\hline 2014 & $\begin{array}{c}0.003 \\
(0.004)\end{array}$ & $\begin{array}{c}0.003 \\
(0.003)\end{array}$ & $\begin{array}{c}0.005 \\
(0.004)\end{array}$ & $\begin{array}{c}0.003 \\
(0.004)\end{array}$ & $\begin{array}{c}0.005 \\
(0.004)\end{array}$ \\
\hline 2015 & $\begin{array}{l}-0.001 \\
(0.005)\end{array}$ & $\begin{array}{l}-0.001 \\
(0.003)\end{array}$ & $\begin{array}{c}0.003 \\
(0.005)\end{array}$ & $\begin{array}{l}-0.001 \\
(0.005)\end{array}$ & $\begin{array}{c}0.002 \\
(0.005)\end{array}$ \\
\hline 2016 & $\begin{array}{l}-0.004 \\
(0.005)\end{array}$ & $\begin{array}{l}-0.005 \\
(0.004)\end{array}$ & $\begin{array}{c}0.001 \\
(0.005)\end{array}$ & $\begin{array}{l}-0.005 \\
(0.005)\end{array}$ & $\begin{array}{l}-0.002 \\
(0.005)\end{array}$ \\
\hline \multicolumn{6}{|l|}{$\underline{\text { State Market Factors }}$} \\
\hline \multicolumn{6}{|l|}{ Labor Costs } \\
\hline $\ln$ (median real hourly wage) & $\begin{array}{c}0.015 \\
(0.014)\end{array}$ & $\begin{array}{c}0.012 \\
(0.011)\end{array}$ & $\begin{array}{c}0.005 \\
(0.014)\end{array}$ & $\begin{array}{c}0.011 \\
(0.014)\end{array}$ & - \\
\hline $\ln (25$ th percentile real hourly wage $)$ & - & - & - & - & $\begin{array}{c}0.001 \\
(0.016)\end{array}$ \\
\hline State Minimum Wage (relative) ${ }^{3}$ & $\begin{array}{l}-0.003 \\
(0.011)\end{array}$ & $\begin{array}{c}-0.004 \\
(0.011)\end{array}$ & $\begin{array}{c}0.004 \\
(0.009)\end{array}$ & $\begin{array}{c}-0.003 \\
(0.011)\end{array}$ & $\begin{array}{c}-0.006 \\
(0.011)\end{array}$ \\
\hline
\end{tabular}


Table 3 (continued)

\begin{tabular}{|c|c|c|c|c|c|}
\hline $\begin{array}{l}\text { Variables } \\
\text { (by category) }\end{array}$ & $\begin{array}{c}\text { (1) } \\
\text { Baseline } \\
\text { specification (with } \\
\text { state market factors) }\end{array}$ & $\begin{array}{c}(2) \\
\text { (1) with labor } \\
\text { force rather than } \\
\text { pop shares }\end{array}$ & $\begin{array}{l}\text { (3) } \\
\text { (1) with } \\
\text { occupation } \\
\text { rather than } \\
\text { industry }\end{array}$ & $\begin{array}{l}\text { (4) } \\
\text { (1) with } \\
\text { occupation } \\
\text { added }\end{array}$ & $\begin{array}{l}\text { (5) } \\
\text { (1) with } 25 \text { th } \\
\text { percentile wage } \\
\text { rather than } \\
\text { median }\end{array}$ \\
\hline \multicolumn{6}{|l|}{ Industry Shares ${ }^{1}$} \\
\hline Construction & $\begin{array}{l}-0.276^{* * *} \\
(0.053)\end{array}$ & $\begin{array}{l}-0.206^{* * *} \\
(0.061)\end{array}$ & - & $\begin{array}{l}-0.341^{* * *} \\
(0.066)\end{array}$ & $\begin{array}{l}-0.280^{* * *} \\
(0.052)\end{array}$ \\
\hline Manufacturing & $\begin{array}{c}0.029 \\
(0.070)\end{array}$ & $\begin{array}{c}0.039 \\
(0.073)\end{array}$ & - & $\begin{array}{c}0.104 \\
(0.117)\end{array}$ & $\begin{array}{c}0.028 \\
(0.071)\end{array}$ \\
\hline Wholesale trade & $\begin{array}{l}-0.898^{* * *} \\
(0.241)\end{array}$ & $\begin{array}{l}-0.898^{* * *} \\
(0.230)\end{array}$ & - & $\begin{array}{l}-0.822 * * * \\
(0.264)\end{array}$ & $\begin{array}{l}-0.907 * * * \\
(0.234)\end{array}$ \\
\hline Retail trade & $\begin{array}{l}-0.130 \\
(0.131)\end{array}$ & $\begin{array}{l}-0.160 \\
(0.132)\end{array}$ & - & $\begin{array}{l}-0.181 \\
(0.130)\end{array}$ & $\begin{array}{l}-0.163 \\
(0.131)\end{array}$ \\
\hline Transportation/comm/utilities & $\begin{array}{l}0.401^{* *} \\
(0.174)\end{array}$ & $\begin{array}{c}0.419^{* *} \\
(0.168)\end{array}$ & - & $\begin{array}{c}0.372 * \\
(0.202)\end{array}$ & $\begin{array}{c}0.382 * * \\
(0.173)\end{array}$ \\
\hline Information & $\begin{array}{l}-0.155 \\
(0.187)\end{array}$ & $\begin{array}{l}-0.111 \\
(0.167)\end{array}$ & - & $\begin{array}{l}-0.117 \\
(0.188)\end{array}$ & $\begin{array}{l}-0.167 \\
(0.185)\end{array}$ \\
\hline Financial activities & $\begin{array}{l}-0.054 \\
(0.132)\end{array}$ & $\begin{array}{c}0.024 \\
(0.126)\end{array}$ & - & $\begin{array}{l}-0.054 \\
(0.142)\end{array}$ & $\begin{array}{l}-0.056 \\
(0.130)\end{array}$ \\
\hline Professional/business services & $\begin{array}{l}-0.096 \\
(0.080)\end{array}$ & $\begin{array}{l}-0.068 \\
(0.087)\end{array}$ & - & $\begin{array}{l}-0.065 \\
(0.075)\end{array}$ & $\begin{array}{l}-0.115 \\
(0.080)\end{array}$ \\
\hline Leisure \& hospitality & $\begin{array}{l}0.356^{* * * *} \\
(0.122)\end{array}$ & $\begin{array}{l}0.310^{* * * *} \\
(0.111)\end{array}$ & - & $\begin{array}{l}0.404 * * * \\
(0.135)\end{array}$ & $\begin{array}{l}0.341 * * * \\
(0.117)\end{array}$ \\
\hline Education \& health services & $\begin{array}{c}0.194 * * \\
(0.086)\end{array}$ & $\begin{array}{l}0.256^{* * * *} \\
(0.088)\end{array}$ & - & $\begin{array}{l}0.218 * * * \\
(0.082)\end{array}$ & $\begin{array}{l}0.178^{* *} \\
(0.083)\end{array}$ \\
\hline Other services & $\begin{array}{l}0.480 * * \\
(0.234)\end{array}$ & $\begin{array}{l}0.485^{* *} \\
(0.227)\end{array}$ & - & $\begin{array}{l}0.542 * * \\
(0.212)\end{array}$ & $\begin{array}{l}0.473 * * \\
(0.237)\end{array}$ \\
\hline \multicolumn{6}{|l|}{$\begin{array}{l}\text { Population/Labor Force Shares } \\
{\text { (age/gender })^{1,2}}\end{array}$} \\
\hline All 16-24 & $\begin{array}{c}-0.008 \\
(0.090)\end{array}$ & $\begin{array}{c}0.014 \\
(0.041)\end{array}$ & $\begin{array}{c}0.183^{*} \\
(0.096)\end{array}$ & $\begin{array}{c}0.008 \\
(0.096)\end{array}$ & $\begin{array}{c}-0.003 \\
(0.089)\end{array}$ \\
\hline Men 25-34 & $\begin{array}{c}0.415 \\
(0.367)\end{array}$ & $\begin{array}{c}0.030 \\
(0.041)\end{array}$ & $\begin{array}{c}0.185 \\
(0.416)\end{array}$ & $\begin{array}{c}0.455 \\
(0.377)\end{array}$ & $\begin{array}{c}0.432 \\
(0.365)\end{array}$ \\
\hline Women 25-34 & $\begin{array}{l}-0.482 \\
(0.398)\end{array}$ & $\begin{array}{l}-0.036 \\
(0.057)\end{array}$ & $\begin{array}{l}-0.143 \\
(0.480)\end{array}$ & $\begin{array}{l}-0.481 \\
(0.413)\end{array}$ & $\begin{array}{l}-0.484 \\
(0.402)\end{array}$ \\
\hline Men 35-54 & $\begin{array}{l}-0.323 \\
(0.308)\end{array}$ & $\mathrm{N} / \mathrm{A}$ & $\begin{array}{l}-0.335 \\
(0.353)\end{array}$ & $\begin{array}{l}-0.303 \\
(0.325)\end{array}$ & $\begin{array}{l}-0.270 \\
(0.326)\end{array}$ \\
\hline Women $35-54$ & $\begin{array}{c}0.024 \\
(0.294)\end{array}$ & $\begin{array}{l}-0.050 \\
(0.064)\end{array}$ & $\begin{array}{c}0.008 \\
(0.337)\end{array}$ & $\begin{array}{c}0.043 \\
(0.305)\end{array}$ & $\begin{array}{l}-0.006 \\
(0.295)\end{array}$ \\
\hline All 55-64 & $\begin{array}{c}0.048 \\
(0.102)\end{array}$ & $\begin{array}{c}0.002 \\
(0.034)\end{array}$ & $\begin{array}{l}-0.026 \\
(0.113)\end{array}$ & $\begin{array}{c}0.050 \\
(0.106)\end{array}$ & $\begin{array}{c}0.024 \\
(0.105)\end{array}$ \\
\hline All 65+ & $\begin{array}{l}-0.109 \\
(0.079)\end{array}$ & $\begin{array}{c}0.094 \\
(0.060)\end{array}$ & $\begin{array}{c}0.037 \\
(0.110)\end{array}$ & $\begin{array}{l}-0.082 \\
(0.079)\end{array}$ & $\begin{array}{l}-0.129 \\
(0.079)\end{array}$ \\
\hline
\end{tabular}


Table 3 (continued)

\begin{tabular}{|c|c|c|c|c|c|}
\hline $\begin{array}{l}\text { Variables } \\
\text { (by category) }\end{array}$ & $\begin{array}{c}\text { (1) } \\
\text { Baseline } \\
\text { specification (with } \\
\text { state market factors) }\end{array}$ & $\begin{array}{l}\text { (2) } \\
\text { (1) with labor } \\
\text { force rather than } \\
\text { pop shares }\end{array}$ & $\begin{array}{l}\text { (3) } \\
\text { (1) with } \\
\text { occupation } \\
\text { rather than } \\
\text { industry }\end{array}$ & $\begin{array}{l}\text { (4) } \\
\text { (1) with } \\
\text { occupation } \\
\text { added }\end{array}$ & $\begin{array}{l}(5) \\
\text { (1) with } 25 \text { th } \\
\text { percentile wage } \\
\text { rather than } \\
\text { median }\end{array}$ \\
\hline \multicolumn{6}{|l|}{$\underline{\text { Occupation Shares }}^{1}$} \\
\hline Management, business, financial & - & - & $\begin{array}{c}0.020 \\
(0.089)\end{array}$ & $\begin{array}{l}-0.063 \\
(0.094)\end{array}$ & - \\
\hline Professional and related & - & - & $\begin{array}{c}0.018 \\
(0.090)\end{array}$ & $\begin{array}{l}-0.090 \\
(0.093)\end{array}$ & - \\
\hline Services & - & - & $\begin{array}{c}0.093 \\
(0.116)\end{array}$ & $\begin{array}{l}-0.150 \\
(0.112)\end{array}$ & - \\
\hline Sales and related & - & - & $\begin{array}{c}0.048 \\
(0.086)\end{array}$ & $\begin{array}{l}-0.097 \\
(0.087)\end{array}$ & - \\
\hline Office and admin support & - & - & $\begin{array}{l}-0.177^{* *} \\
(0.090)\end{array}$ & $\begin{array}{l}-0.106 \\
(0.107)\end{array}$ & - \\
\hline Farming, fishing, forestry & - & - & $\begin{array}{l}-0.452 \\
(0.333)\end{array}$ & $\begin{array}{l}-0.536^{*} \\
(0.292)\end{array}$ & - \\
\hline Construction and extraction & - & - & $\begin{array}{l}-0.105 \\
(0.113)\end{array}$ & $\begin{array}{l}-0.031 \\
(0.102)\end{array}$ & - \\
\hline Installation, maintenance, repair & - & - & $\begin{array}{c}0.021 \\
(0.211)\end{array}$ & $\begin{array}{c}0.126 \\
(0.209)\end{array}$ & - \\
\hline Production & - & - & $\begin{array}{c}0.003 \\
(0.120)\end{array}$ & $\begin{array}{l}-0.228 \\
(0.153)\end{array}$ & - \\
\hline State Dummies & Yes & Yes & Yes & Yes & Yes \\
\hline Pseudo $\mathrm{R}^{2}$ & 0.0155 & 0.0155 & 0.0154 & 0.0155 & 0.0155 \\
\hline $\mathrm{N}$ & 714 & 714 & 714 & 714 & 714 \\
\hline
\end{tabular}

${ }^{1}$ Omitted categories are as follows: government for the industry categories; transportation and material moving for occupations; individuals age $<16$ for the population shares; and men age 35-54 for the labor force shares in column 2 (dropping a category is required because the labor force excludes individuals under the age of 16).

${ }^{2}$ Population shares used in all columns except 2, which uses labor force shares.

${ }^{3}$ Minimum wage measured relative to state median wage (both nominal).

Notes: Standard errors in parentheses (clustered by state). Mean of state civilian employment used for regression weights. 
Table 4: Multinomial Logit Regressions, IPT and VPT, 2003-2016

(full time is the omitted category)

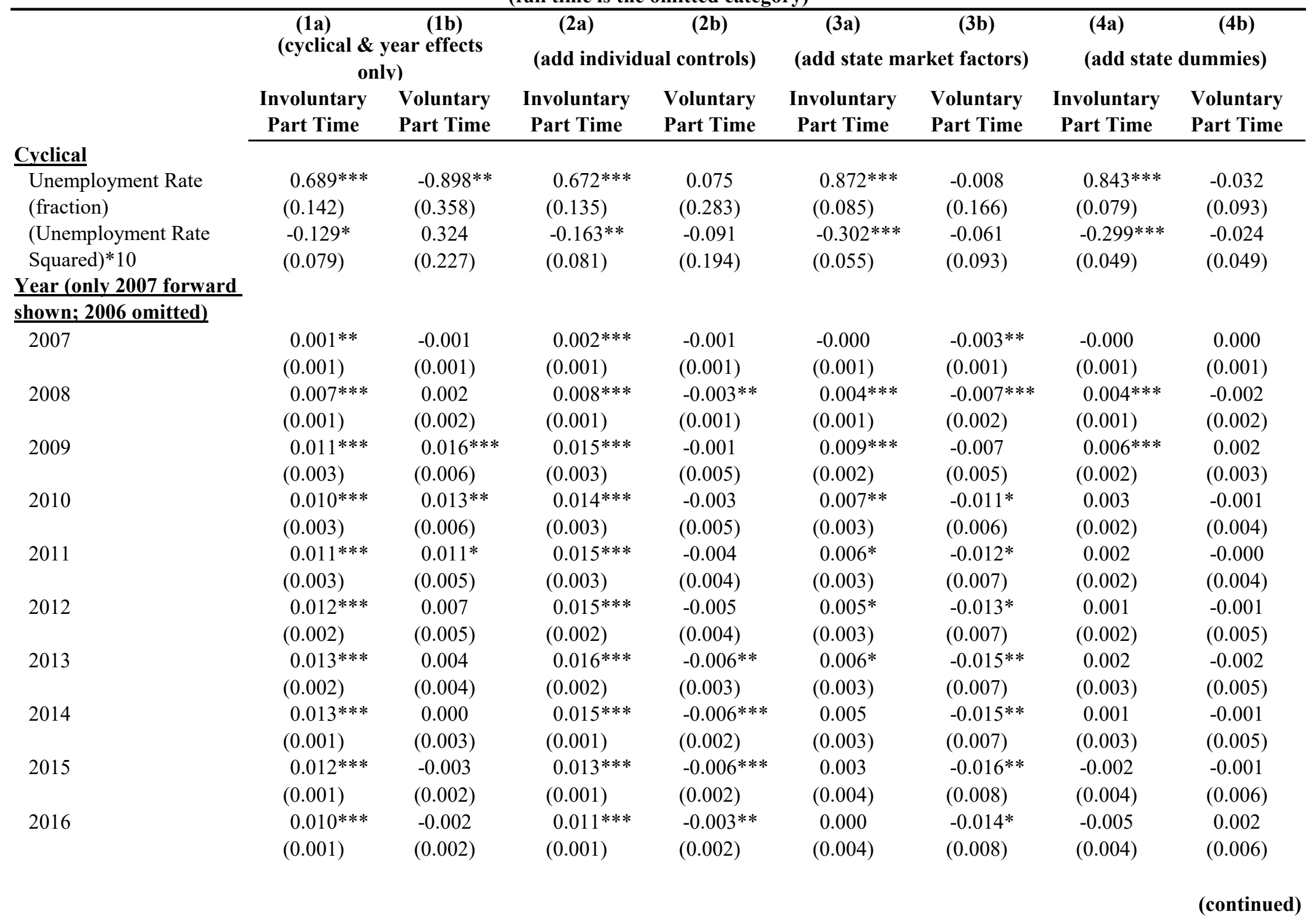


Table 4 (continued)

(1a)

(1b)

Involuntary Voluntary

Part-Time Part-Time (2b)

(2a)

Involuntary

Part-Time
Part-Time (3a)

Involuntary Part-Time (3b)

Voluntary Part-Time (4a)

Involuntary Voluntary

Market Factors (State) Labor Costs

$\ln$ (median real hourly wage)

State Minimum Wage

(relative)

Industry Shares

Construction

Manufacturing

Wholesale trade

Retail trade

Transportation/utilities

Information

Financial activities

Professional/business

services

Leisure \& hospitality

Education \& health services

Other services

\begin{tabular}{|c|c|c|c|}
\hline $0.021 * *$ & $0.084 * * *$ & 0.019 & -0.010 \\
\hline$(0.009)$ & $(0.023)$ & $(0.012)$ & $(0.020)$ \\
\hline $0.023 *$ & $0.046 * *$ & -0.007 & 0.011 \\
\hline$(0.014)$ & $(0.023)$ & $(0.009)$ & $(0.012)$ \\
\hline-0.079 & 0.093 & $-0.256 * * *$ & -0.138 \\
\hline$(0.068)$ & $(0.119)$ & $(0.048)$ & $(0.086)$ \\
\hline 0.044 & $0.197 * *$ & -0.011 & -0.118 \\
\hline$(0.028)$ & $(0.078)$ & $(0.070)$ & $(0.104)$ \\
\hline 0.022 & 0.052 & $-0.826 * * *$ & 0.421 \\
\hline$(0.106)$ & $(0.223)$ & $(0.207)$ & $(0.417)$ \\
\hline $0.271 * * *$ & 0.093 & -0.189 & 0.109 \\
\hline$(0.067)$ & $(0.217)$ & $(0.127)$ & $(0.254)$ \\
\hline-0.059 & $-0.334 *$ & $0.303 *$ & $0.550 * * *$ \\
\hline$(0.068)$ & $(0.187)$ & $(0.157)$ & $(0.195)$ \\
\hline $0.350 * * *$ & 0.422 & -0.006 & -0.291 \\
\hline$(0.102)$ & $(0.269)$ & $(0.137)$ & $(0.287)$ \\
\hline$-0.103 * *$ & $-0.237^{*}$ & -0.136 & -0.060 \\
\hline$(0.046)$ & $(0.123)$ & $(0.111)$ & $(0.253)$ \\
\hline $0.094 * * *$ & $0.167 * *$ & 0.010 & $-0.266^{* *}$ \\
\hline$(0.032)$ & $(0.082)$ & $(0.074)$ & $(0.123)$ \\
\hline 0.030 & -0.027 & $0.240 * *$ & -0.227 \\
\hline$(0.032)$ & $(0.097)$ & $(0.113)$ & $(0.201)$ \\
\hline 0.038 & $0.266 * * *$ & $0.166^{* *}$ & -0.131 \\
\hline$(0.032)$ & $(0.066)$ & $(0.068)$ & $(0.139)$ \\
\hline 0.068 & -0.276 & $0.409 * *$ & -0.125 \\
\hline$(0.089)$ & $(0.259)$ & $(0.184)$ & $(0.324)$ \\
\hline
\end{tabular}


Table 4 (continued)

(1a)

(1b)

(2a)

(2b)

(3a)

(3b)

(4a)

(4b)

Involuntary Voluntary Involuntary Voluntary Involuntary Voluntary Involuntary Voluntary

Part-Time Part-Time Part-Time Part-Time Part-Time Part-Time Part-Time Part-Time

$\underline{\text { Population Shares }}$ (gender/age) All 16-24

Men 25-34

Women 25-34

Time

Part-Time

Part-Time

Part-Time

Part-Time

\begin{tabular}{|c|c|c|c|c|c|c|c|c|}
\hline Women 25-34 & - & & - & & $\begin{array}{l}-0.492 \\
(0.310)\end{array}$ & $\begin{array}{l}-0.538 \\
(0.817)\end{array}$ & $\begin{array}{l}-0.022 \\
(0.285)\end{array}$ & $\begin{array}{c}0.840 \\
(0.569)\end{array}$ \\
\hline Men 35-54 & - & & - & & $\begin{array}{c}0.441 * \\
(0.241)\end{array}$ & $\begin{array}{c}0.557 \\
(0.535)\end{array}$ & $\begin{array}{l}-0.167 \\
(0.214)\end{array}$ & $\begin{array}{l}-0.122 \\
(0.457)\end{array}$ \\
\hline Women $35-54$ & - & & - & & $\begin{array}{l}-0.873 * * * \\
(0.227)\end{array}$ & $\begin{array}{l}-1.620 * * * \\
(0.521)\end{array}$ & $\begin{array}{c}0.098 \\
(0.197)\end{array}$ & $\begin{array}{c}0.238 \\
(0.435)\end{array}$ \\
\hline All 55-64 & - & & - & & $\begin{array}{l}0.239 * * \\
(0.098)\end{array}$ & $\begin{array}{l}-0.038 \\
(0.239)\end{array}$ & $\begin{array}{l}0.214 * * * \\
(0.072)\end{array}$ & $\begin{array}{l}-0.241 \\
(0.159)\end{array}$ \\
\hline All 65+ & - & & - & & $\begin{array}{l}-0.110^{*} \\
(0.062)\end{array}$ & $\begin{array}{l}-0.345^{* *} \\
(0.152)\end{array}$ & $\begin{array}{l}-0.111 \\
(0.070)\end{array}$ & $\begin{array}{l}0.232 * * \\
(0.103)\end{array}$ \\
\hline Individual Controls & & No & & Yes & \multicolumn{2}{|c|}{ Yes } & \multicolumn{2}{|c|}{ Yes } \\
\hline State Dummies & & No & & No & \multicolumn{2}{|c|}{ No } & \multicolumn{2}{|c|}{ Yes } \\
\hline $\mathrm{N}$ & & 946012 & & 946012 & \multicolumn{2}{|c|}{9460124} & \multicolumn{2}{|c|}{9460124} \\
\hline Log Likelihood & & -553078 & & -44989 & \multicolumn{2}{|c|}{-4485384.8} & \multicolumn{2}{|c|}{-4480220.9} \\
\hline Pseudo-R2 & & 0.004 & & 0.190 & \multicolumn{2}{|c|}{0.193} & \multicolumn{2}{|c|}{0.194} \\
\hline
\end{tabular}

$* * * \mathrm{p}<0.01, * * \mathrm{p}<0.05, * \mathrm{p}<0.10$

Notes: Standard errors (clustered by state) in parentheses. Sample includes nonagricultural wage and salary or self-employed (unincorporated) workers age 16 and over who worked positive hours in the survey week and whose hours data were not allocated. Individual controls include age ( 7 categories)*gender*marital status interactions, education level (5), race/ethnicity (5), veteran status, major industry (13), and major occupation. See Table 3 for notes on state market factors. 
Table 5: Self-Employment and Multiple Job Holding,

Logit Regression Results, 2003-16

(dependent variables as indicated; average marginal effects reported)

(1)

Self-employed

Dependent variable:
(2)

Multiple job holder
(3)

Self-employed on second job ${ }^{1}$

Explanatory Variables

(by category)

State variables

IPT rate

$0.163^{* * *}$

$0.168 * * *$

$0.045^{* *}$

Unemployment Rate (fraction)

$(0.046)$

(0.039)

$(0.022)$

$-0.065$

0.030

0.029

(Unemp Rate Squared)*10

(0.089)

(0.066)

$(0.040)$

0.012

$-0.045$

$-0.024$

(0.052)

(0.039)

(0.023)

Year (2006 omitted)

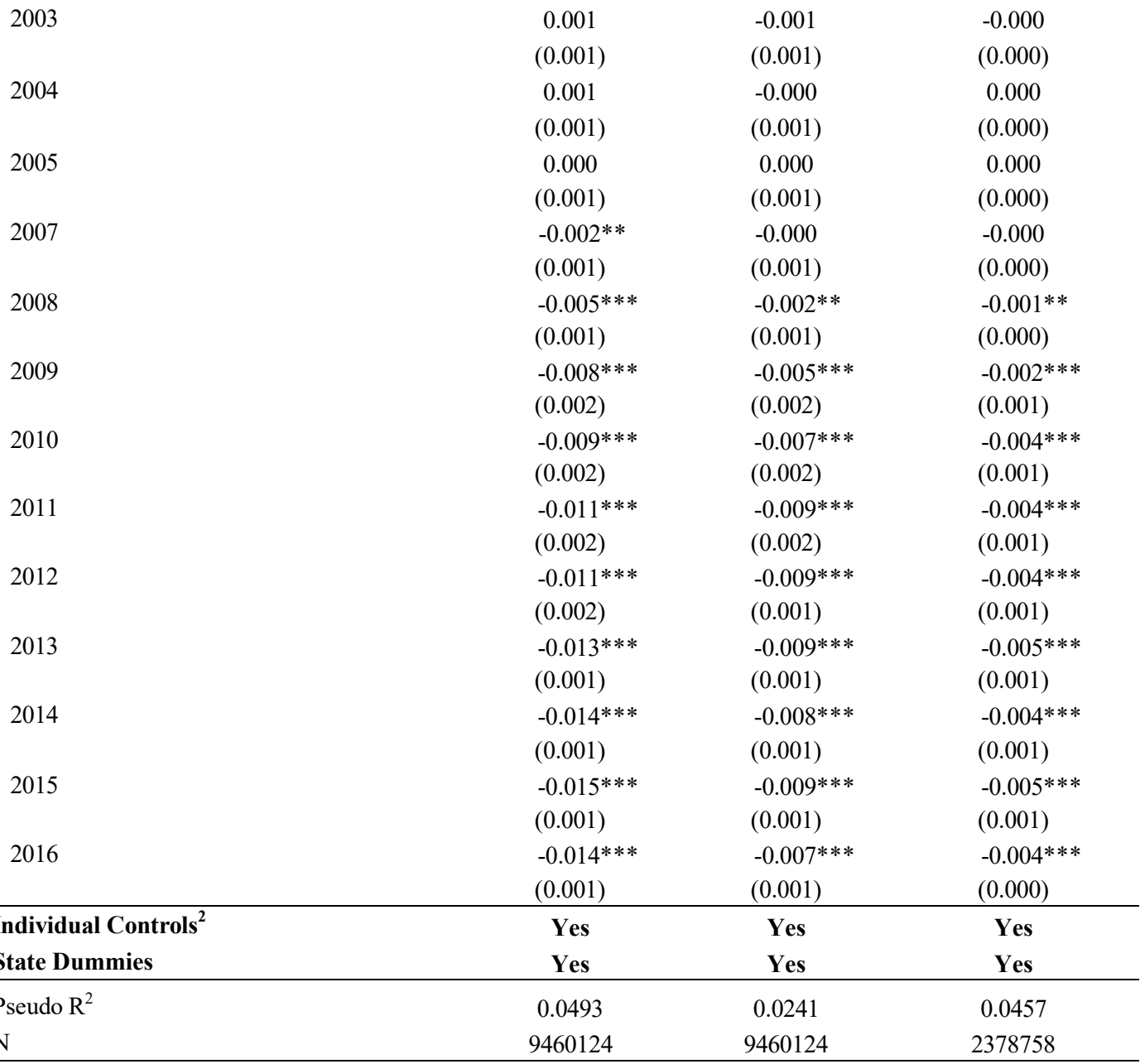

$* * * \mathrm{p}<0.01, * * \mathrm{p}<0.05,{ }^{*} \mathrm{p}<0.10$

${ }^{1}$ Available for multiple job holders, in CPS outgoing rotation groups (quarter sample) only.

${ }^{2}$ Individual controls same as Table 4 (age/gender/marital, education, race/ethnicity), except industry and occupation categories excluded.

Notes: Standard errors in parentheses (clustered by state). Sample includes nonagricultural wage and salary or selfemployed (unincorporated) workers age 16 and over who worked positive hours in the survey week and whose hours data were not allocated. 
Table 6: Decomposition of IPT change (2006 base)

(based on average marginal effects from column 1 of Table 3;

fractional contribution to column 1 total in parentheses)

\begin{tabular}{|c|c|c|c|c|c|c|}
\hline & (1) & (2) & (3) & (4) & (5) & (6) \\
\hline Year & $\begin{array}{l}\text { Total change } \\
\text { from } 2006\end{array}$ & $\begin{array}{c}\text { Cyclical } \\
\text { component } \\
\text { (unemployment) }\end{array}$ & $\begin{array}{l}\text { Industry } \\
\text { composition }\end{array}$ & $\begin{array}{l}\text { Age/gender } \\
\text { composition }\end{array}$ & Labor costs & Year effects \\
\hline 2006 & 0.000 & $\begin{array}{c}0.000 \\
(0.000)\end{array}$ & $\begin{array}{c}0.000 \\
(0.000)\end{array}$ & $\begin{array}{c}0.000 \\
(0.000)\end{array}$ & $\begin{array}{c}0.000 \\
(0.000)\end{array}$ & $\begin{array}{c}0.000 \\
(0.000)\end{array}$ \\
\hline 2007 & 0.001 & $\begin{array}{c}0.000 \\
(0.012)\end{array}$ & $\begin{array}{c}0.001 \\
(0.433)\end{array}$ & $\begin{array}{c}0.000 \\
(0.178)\end{array}$ & $\begin{array}{c}0.000 \\
(0.031)\end{array}$ & $\begin{array}{c}0.001 \\
(0.346)\end{array}$ \\
\hline 2008 & 0.012 & $\begin{array}{c}0.004 \\
(0.325)\end{array}$ & $\begin{array}{c}0.003 \\
(0.218)\end{array}$ & $\begin{array}{c}0.001 \\
(0.056)\end{array}$ & $\begin{array}{c}0.000 \\
(0.004)\end{array}$ & $\begin{array}{c}0.005 \\
(0.397)\end{array}$ \\
\hline 2009 & 0.035 & $\begin{array}{c}0.016 \\
(0.444)\end{array}$ & $\begin{array}{c}0.009 \\
(0.248)\end{array}$ & $\begin{array}{c}0.001 \\
(0.039)\end{array}$ & $\begin{array}{c}0.000 \\
(0.010)\end{array}$ & $\begin{array}{c}0.009 \\
(0.258)\end{array}$ \\
\hline 2010 & 0.035 & $\begin{array}{c}0.017 \\
(0.469)\end{array}$ & $\begin{array}{c}0.011 \\
(0.299)\end{array}$ & $\begin{array}{c}0.001 \\
(0.034)\end{array}$ & $\begin{array}{c}0.000 \\
(0.009)\end{array}$ & $\begin{array}{c}0.007 \\
(0.190)\end{array}$ \\
\hline 2011 & 0.033 & $\begin{array}{c}0.015 \\
(0.446)\end{array}$ & $\begin{array}{c}0.011 \\
(0.325)\end{array}$ & $\begin{array}{c}0.002 \\
(0.052)\end{array}$ & $\begin{array}{c}0.000 \\
(0.006)\end{array}$ & $\begin{array}{c}0.006 \\
(0.171)\end{array}$ \\
\hline 2012 & 0.029 & $\begin{array}{c}0.012 \\
(0.414)\end{array}$ & $\begin{array}{c}0.011 \\
(0.370)\end{array}$ & $\begin{array}{c}0.002 \\
(0.063)\end{array}$ & $\begin{array}{c}0.000 \\
(0.001)\end{array}$ & $\begin{array}{c}0.004 \\
(0.152)\end{array}$ \\
\hline 2013 & 0.026 & $\begin{array}{c}0.010 \\
(0.367)\end{array}$ & $\begin{array}{c}0.011 \\
(0.402)\end{array}$ & $\begin{array}{c}0.002 \\
(0.074)\end{array}$ & $\begin{array}{c}0.000 \\
(0.000)\end{array}$ & $\begin{array}{c}0.004 \\
(0.158)\end{array}$ \\
\hline 2014 & 0.020 & $\begin{array}{c}0.006 \\
(0.270)\end{array}$ & $\begin{array}{c}0.010 \\
(0.501)\end{array}$ & $\begin{array}{c}0.002 \\
(0.098)\end{array}$ & $\begin{array}{c}0.000 \\
-(0.002)\end{array}$ & $\begin{array}{c}0.003 \\
(0.133)\end{array}$ \\
\hline 2015 & 0.014 & $\begin{array}{c}0.002 \\
(0.166)\end{array}$ & $\begin{array}{c}0.010 \\
(0.726)\end{array}$ & $\begin{array}{c}0.002 \\
(0.138)\end{array}$ & $\begin{array}{c}0.000 \\
(0.011)\end{array}$ & $\begin{array}{l}-0.001 \\
-(0.040)\end{array}$ \\
\hline 2016 & 0.011 & $\begin{array}{c}0.001 \\
(0.087)\end{array}$ & $\begin{array}{c}0.011 \\
(1.010)\end{array}$ & $\begin{array}{c}0.002 \\
(0.181)\end{array}$ & $\begin{array}{c}0.000 \\
(0.028)\end{array}$ & $\begin{array}{l}-0.003 \\
-(0.305)\end{array}$ \\
\hline
\end{tabular}

Note: See text (Section VI) for description of decomposition methodology. 
Table 7: Decomposition of IPT change (2006 base):

Selected Industry Share Effects, 2016 Only

(based on average marginal effects from column 1 of Table 3;

fractional contribution to column 1 total in parentheses)

\begin{tabular}{ccccccc}
$(1)$ & $(2)$ & $(3)$ & $(4)$ & $(5)$ & $(6)$ & $(7)$ \\
\hline \multirow{2}{*}{$\begin{array}{c}\text { Total change } \\
\text { from 2006 }\end{array}$} & Construction & $\begin{array}{c}\text { Wholesale } \\
\text { trade }\end{array}$ & $\begin{array}{c}\text { Transportation/ } \\
\text { comm/utilities }\end{array}$ & $\begin{array}{c}\text { Leisure \& } \\
\text { hospitality }\end{array}$ & $\begin{array}{c}\text { Education } \\
\text { \& health } \\
\text { services }\end{array}$ & $\begin{array}{c}\text { Other } \\
\text { services }\end{array}$ \\
0.0106 & 0.0023 & 0.0018 & 0.0005 & 0.0031 & 0.0035 & -0.0001 \\
& $(0.213)$ & $(0.165)$ & $(0.050)$ & $(0.295)$ & $(0.328)$ & $-(0.005)$ \\
\hline
\end{tabular}

Note: See text (Section VI) for description of decomposition methodology. 


\section{Appendix A: State Data Sources and Definitions}

The definitions and sources for the primary variables used in the state-level panel analysis (and incorporated into the analyses using CPS individual data) are as follows.

1) Involuntary part-time employment (IPT) rate. We formed this variable using annual averages from the state labor force and labor underutilization series, available from 2003 forward from the BLS Local Area Unemployment Statistics (LAUS) program: http://www.bls.gov/lau/stalt_archived.htm. The IPT rate as a share of civilian employment is calculated by backing it out from the underutilization series U5 and U6 (which includes the IPT group) along with the employment and labor force series.

2) Unemployment rate and labor force participation. These are also obtained from the BLS LAUS program.

3) State GDP. From the U.S. Bureau of Economic Analysis (BEA) Regional Economic Accounts.

\section{4) Labor costs:}

a) Real median and percentile wage. Median and percentile $\left(25^{\text {th }}\right.$ and $\left.10^{\text {th }}\right)$ hourly wage data for each state are from the BLS Occupational Employment Statistics program (OES, http://www.bls.gov/oes/tables.htm), using data for all occupations for each year. The wage series are deflated using the BEA's GDP PCE deflator.

b) Minimum wage. Minimum wages are compiled from the US Department of Labor minimum wage historical tables

(http://www.dol.gov/whd/state/stateMinWageHis.htm). When there is no listed minimum wage for a year for a particular state, the most recent listed minimum wage for that state is used. If there are no data for a state at all or the legislated state 
minimum is below the U.S. minimum, the U.S. minimum wage is used. When a range is listed (in the case that different laws apply to different types of enterprises), then the upper bound is used.

5) Industry employment shares. Calculated using BLS state nonfarm payroll employment data, available at: http://www.bls.gov/sae/tables.htm.

6) Occupation employment shares. Calculated using data from the BLS Occupational Employment Statistics program (OES, http://www.bls.gov/oes/tables.htm)

7) Population shares by age/gender. Calculated using the latest available post-censal population estimates released by the U.S. Bureau of the Census. For example, the 2000s data use the 2009 vintage of postcensal estimates, and 2010s data use the 2014 vintage. Historical data are available at http://www.census.gov/popest/data/historical/index.html, and current estimates are available at $\underline{\mathrm{http}} / / / \mathrm{www}$. census.gov/popest/data/index.html.

8) Labor force shares by age/gender. From the BLS LAUS, Expanded State Employment Status Demographic Data (https://www.bls.gov/lau/ex14tables.htm). 
Appendix B: Supplemental Displays 


\section{Figure B1}

\section{Part-Time Employment (actual and adjusted)}
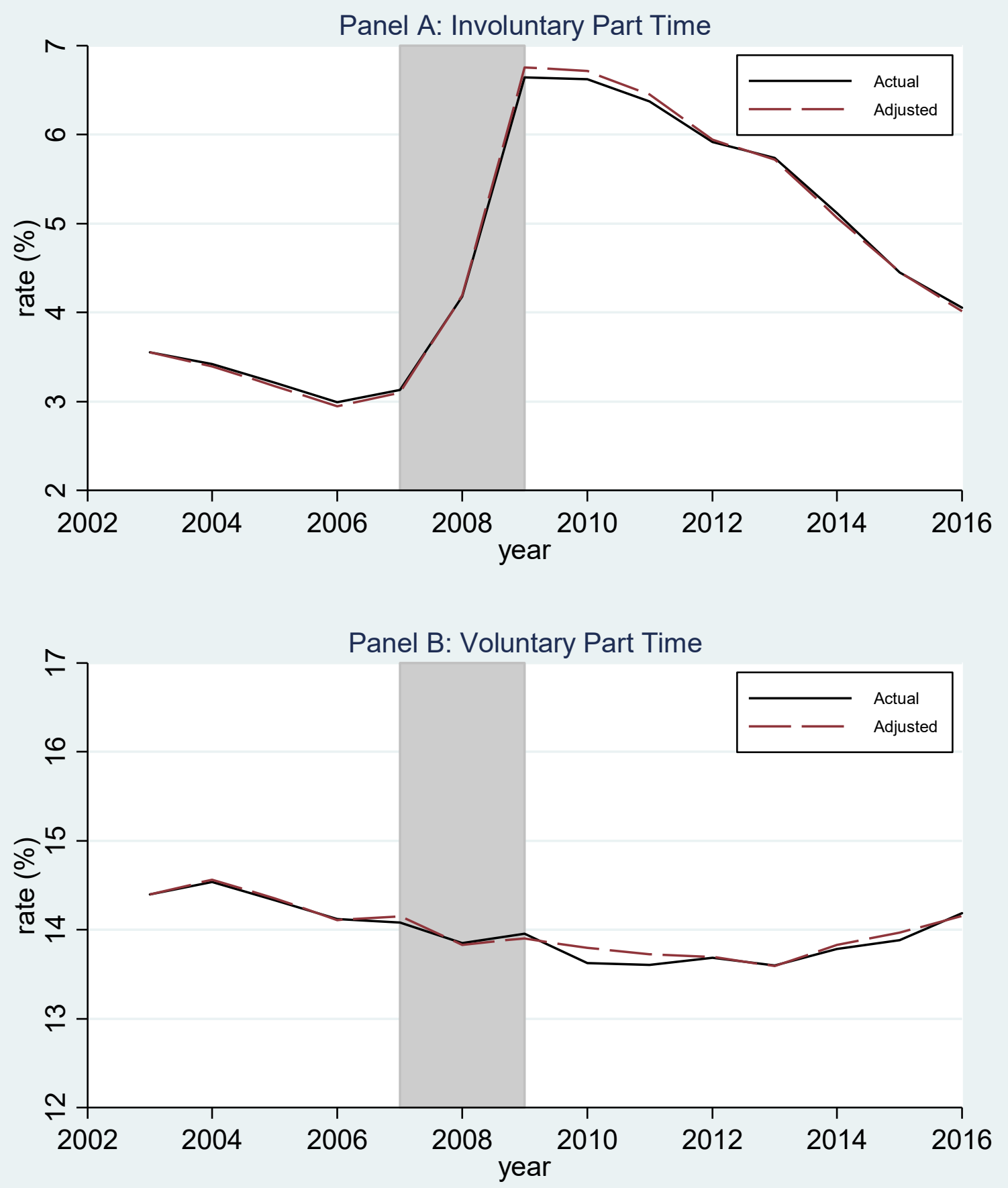

Note: Authors' calculations from CPS data. Adjusted series reflects reweighting to hold individual characteristics at 2003 distribution (see text). Series are measured as shares of civilian employment. Gray area denotes recession period (approximate). 


\section{Figure B2}

\section{Involuntary Part-Time (IPT) Work and Unemployment, by State}
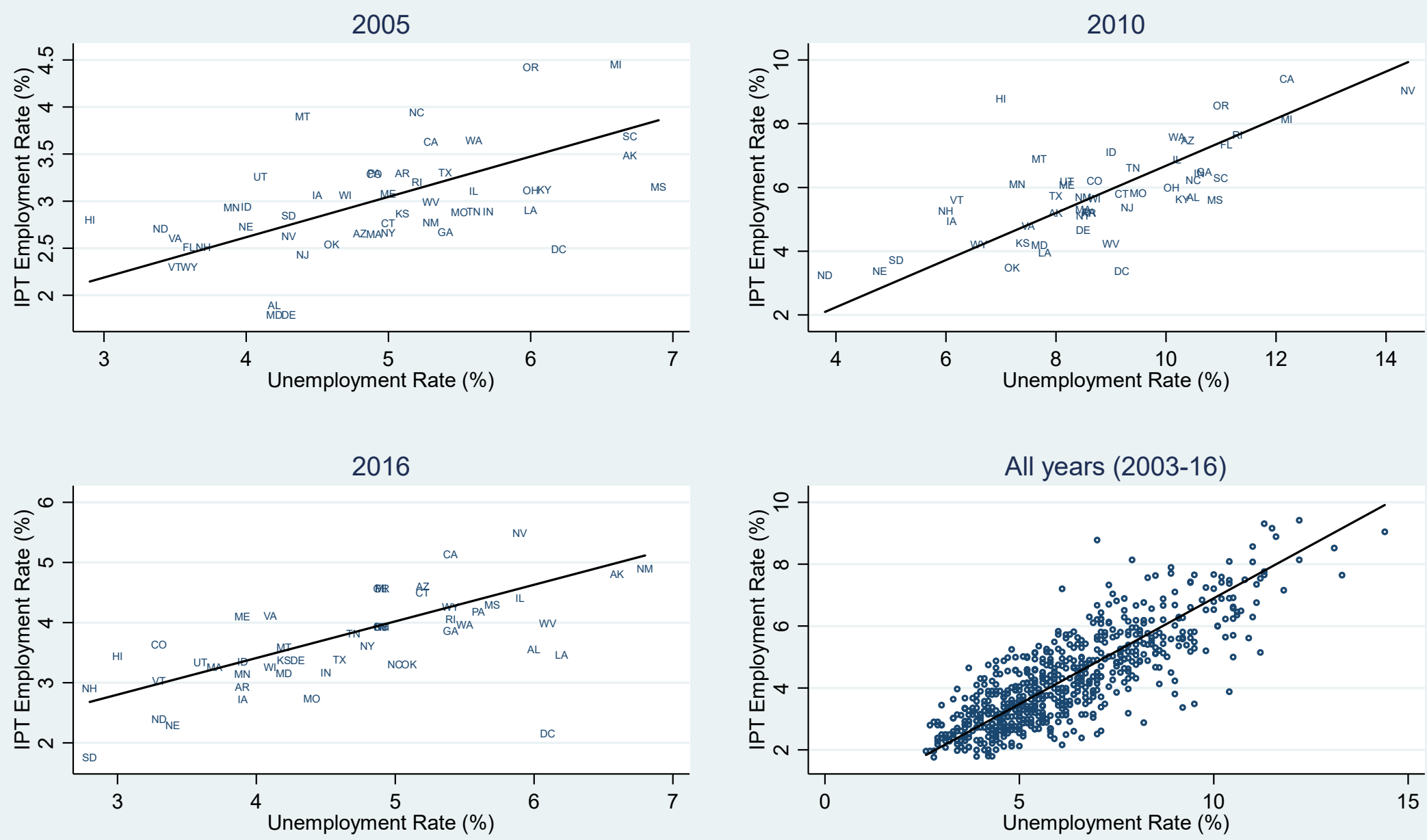

Source: BLS and authors' calculations. IPT employment rate measured as a share of civilian employment. Fitted lines weighted by state employment. 


\section{Figure B3}

\section{Involuntary Part-Time (IPT) Work and Unemployment Changes over Time, All States (by periods)}
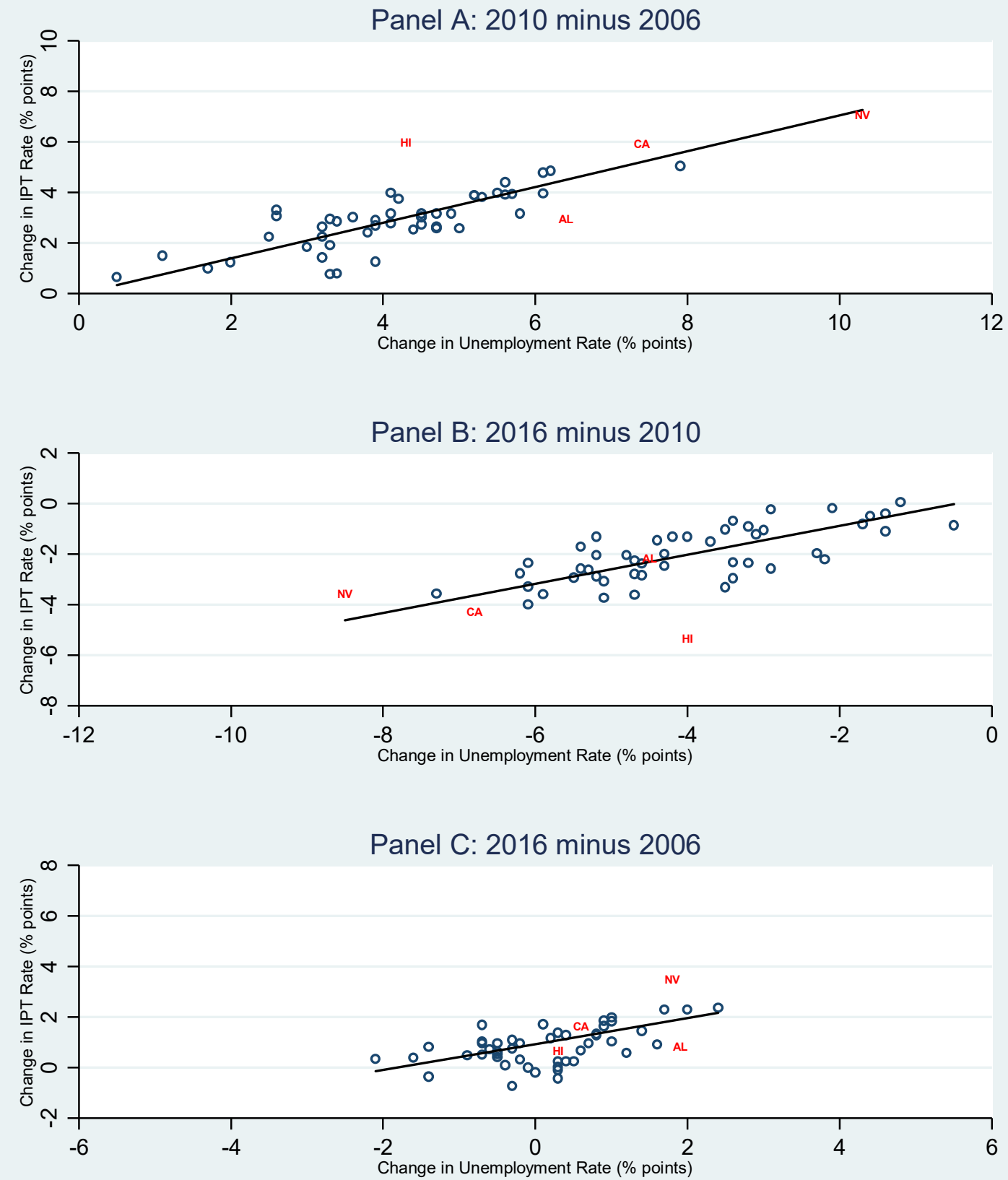

Source: BLS and authors' calculations. IPT employment rate measured as a share of civilian employment. Fitted lines weighted by state employment in base year. 


\section{Figure B4}

Involuntary Part-Time (IPT) Work and Unemployment

Changes over Time, Selected States
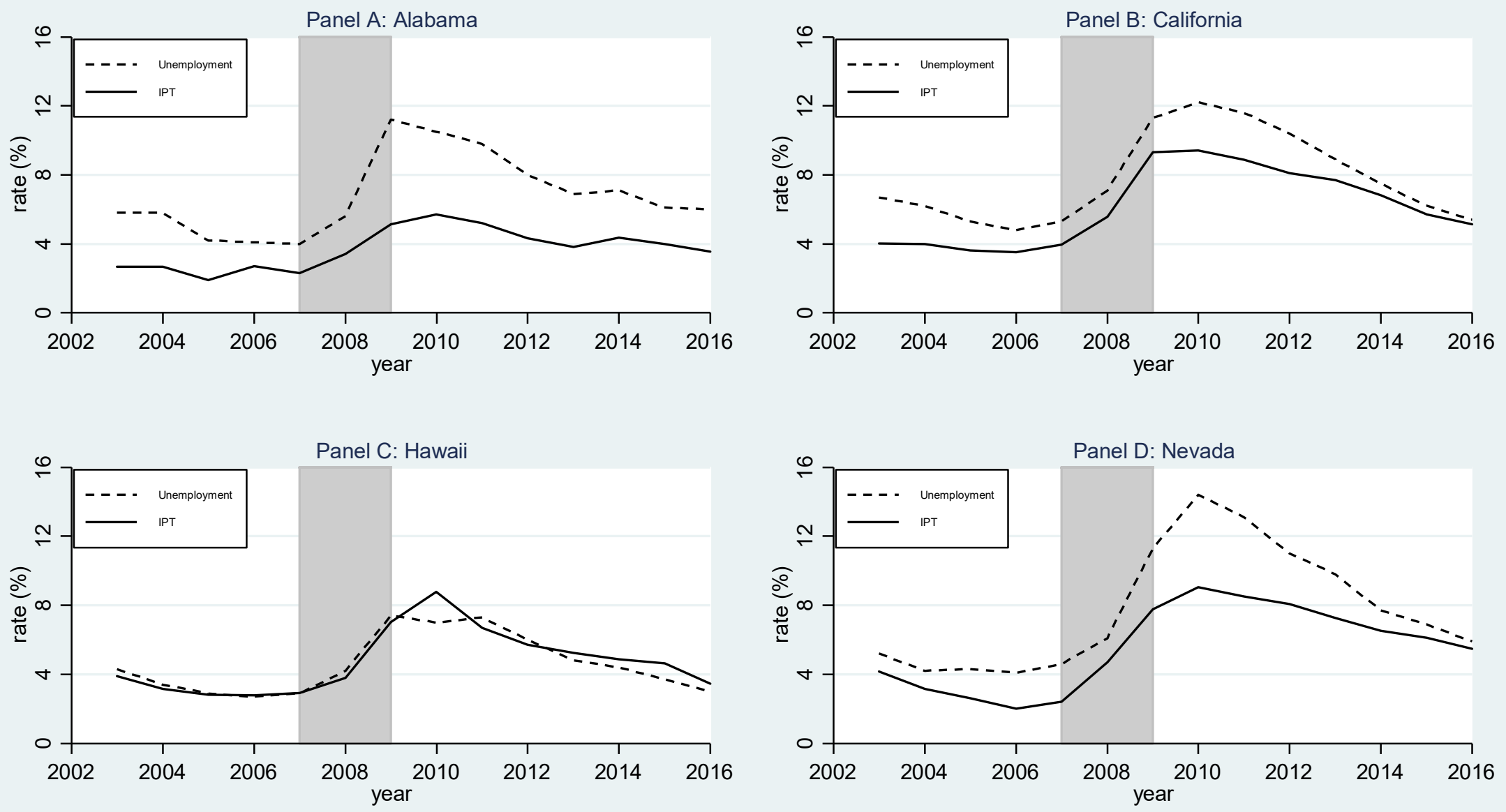

Source: BLS and authors' calculations. IPT employment rate measured as a share of civilian employment. Gray areas denote recession period (approximate). 


\section{Figure B5}

Distribution of Industry Shares across States

Average levels and changes
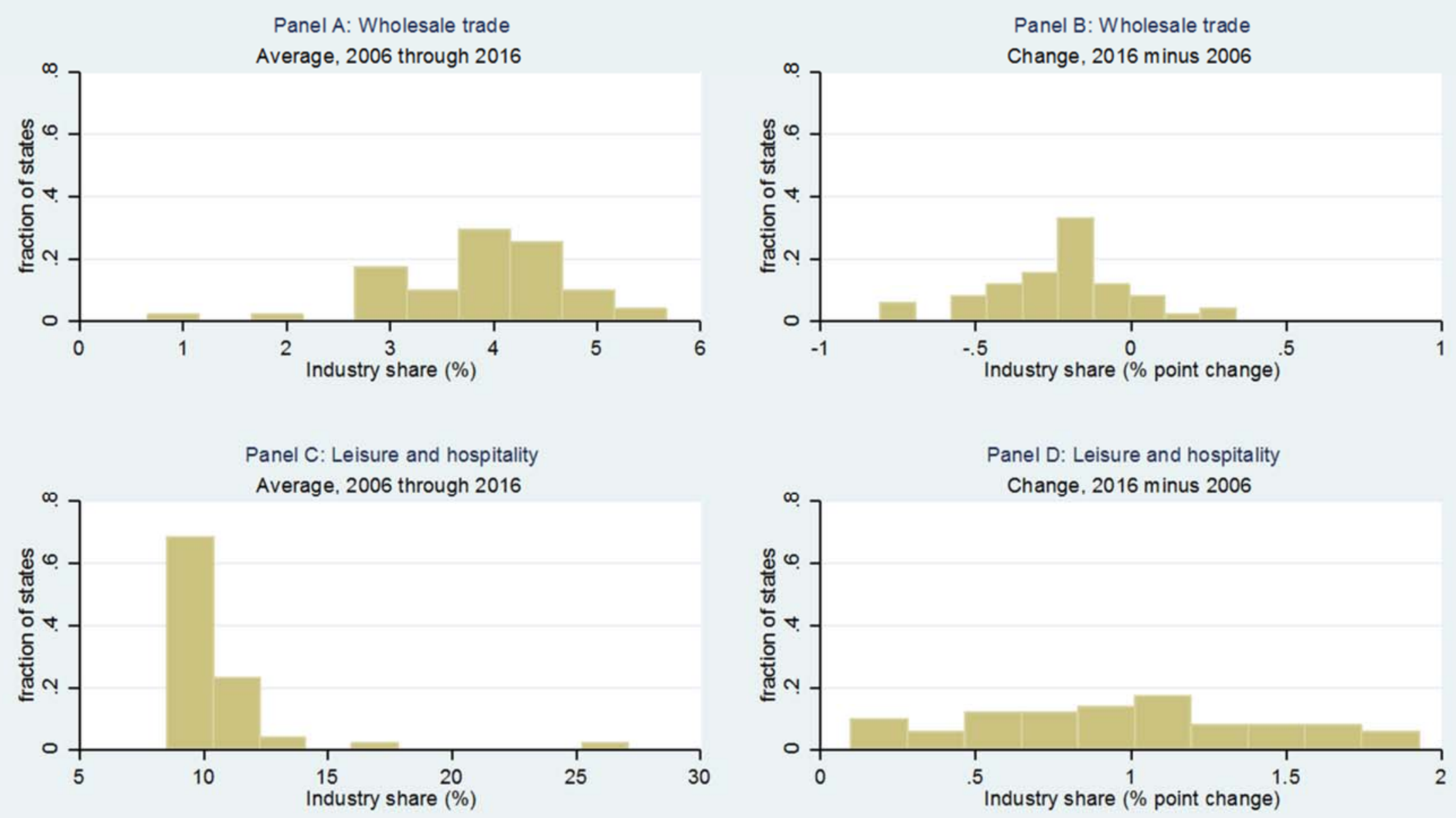

Source: BLS and authors' calculations based on state payroll employment data. 


\section{Figure B6}

\section{Distribution of Population Shares across States}

Average levels and changes

Panel A: Age 16-24

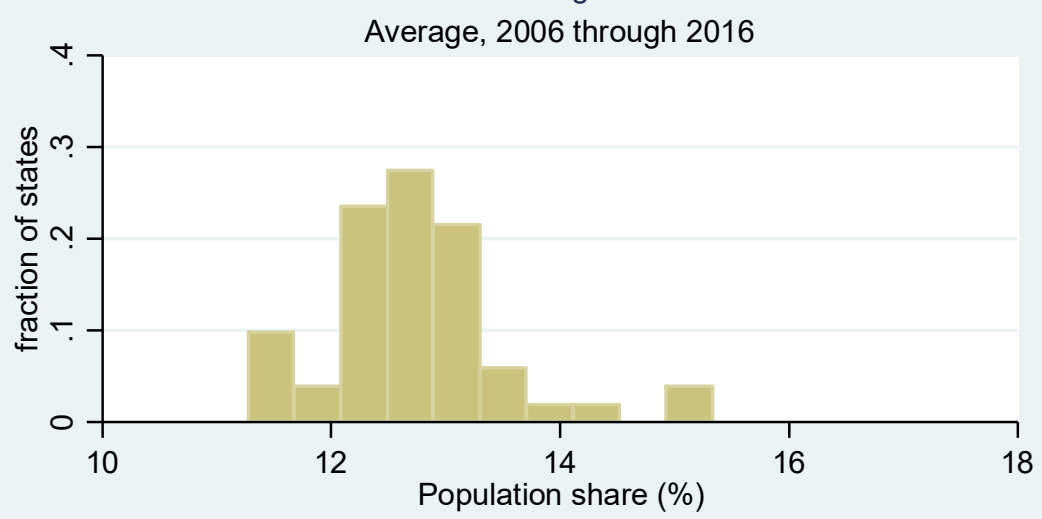

Panel C: Age 65+

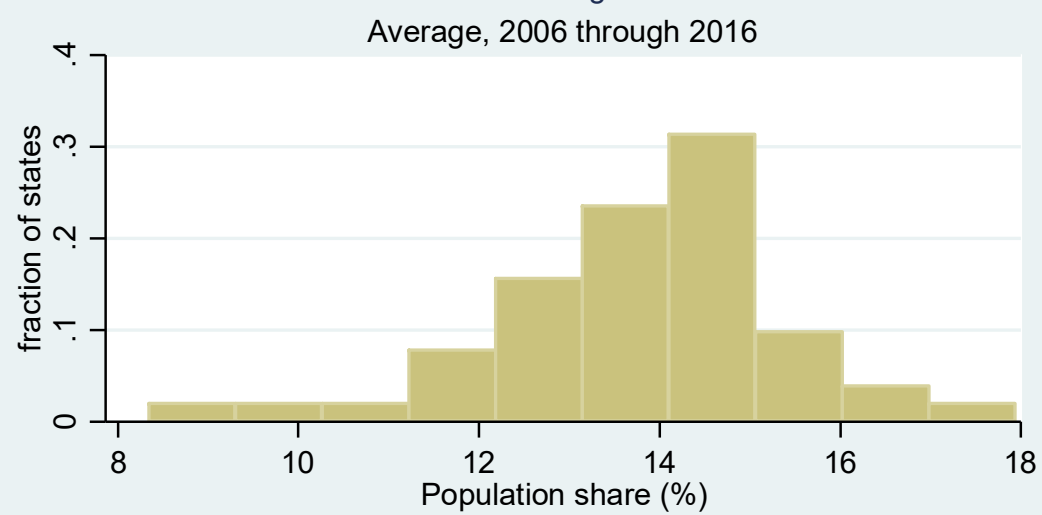

Panel B: Age 16-24

Change, 2016 minus 2006

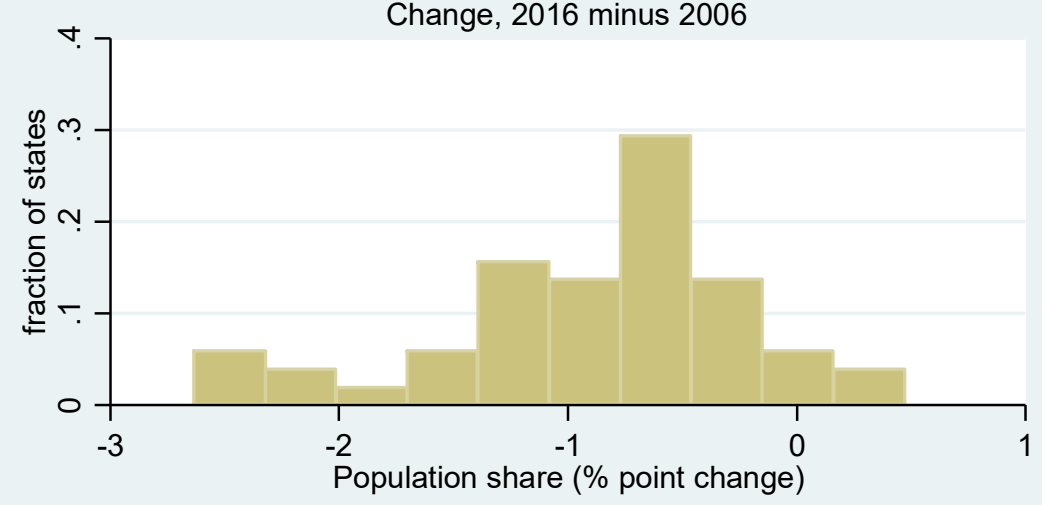

Panel D: Age 65+

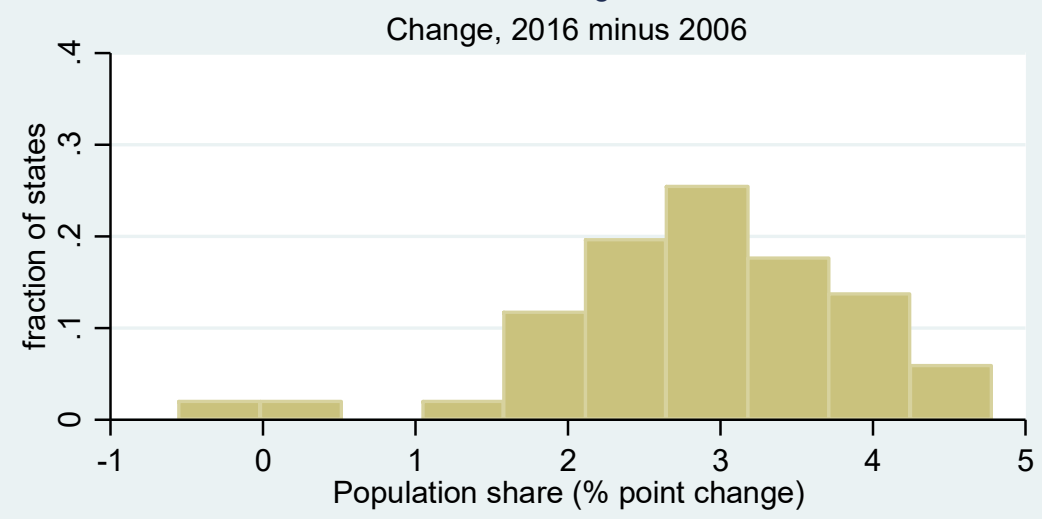

Source: Authors' calculations based on U.S. Census Bureau data. 


\section{Figure B7}

\section{Distribution of Median and Minimum Wage across States}

Average levels and changes

Panel A: Median wage

Average, 2006 through 2016

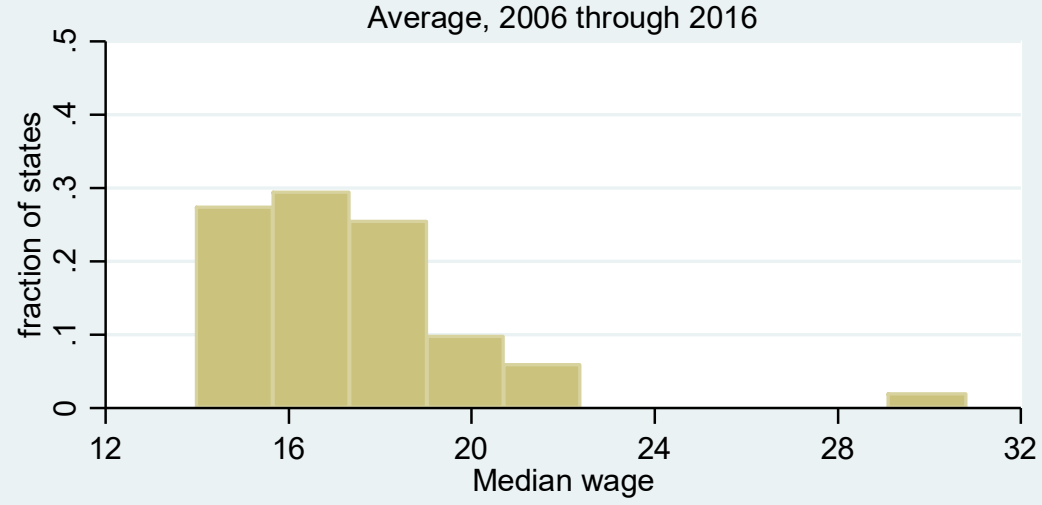

Panel C: Minimum wage (relative)

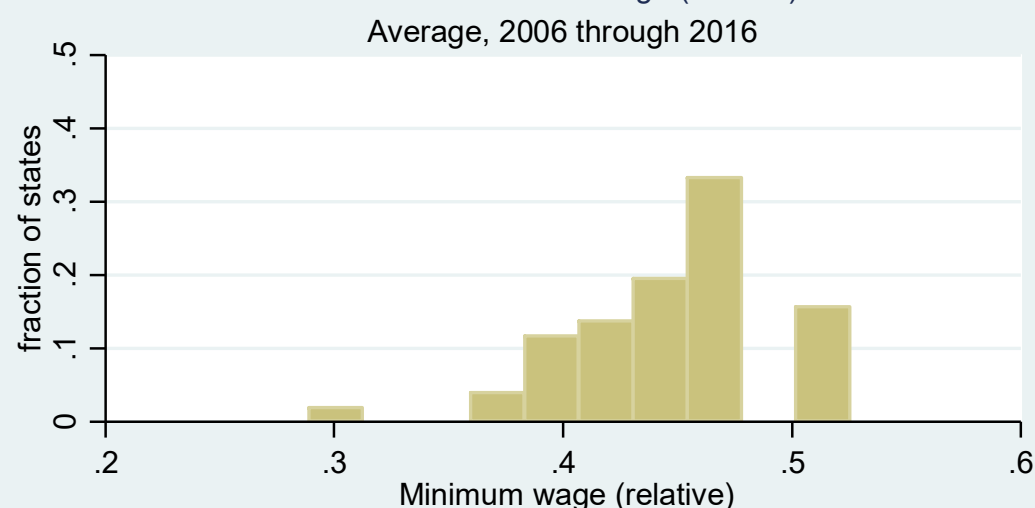

Panel B: Median wage

Change, 2016 minus 2006

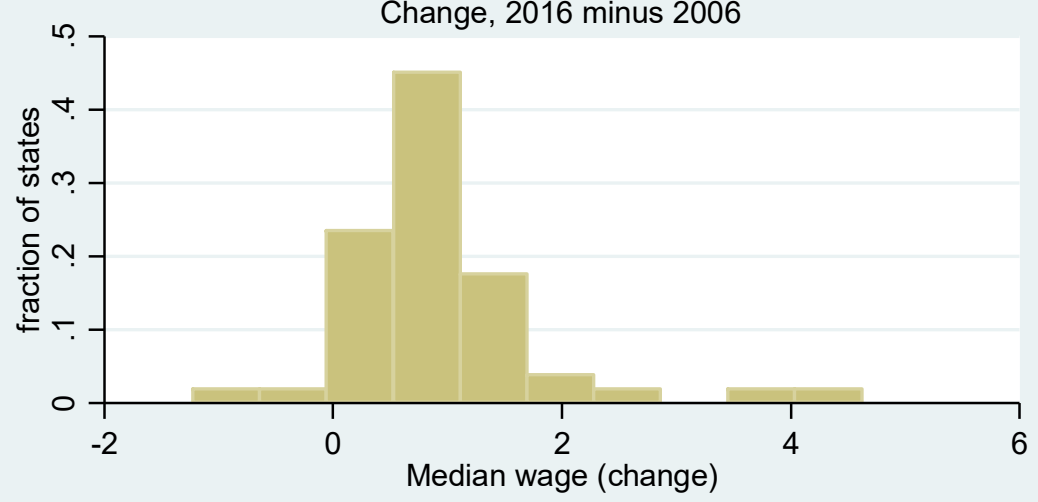

Panel D: Minimum wage (relative) Change, 2016 minus 2006

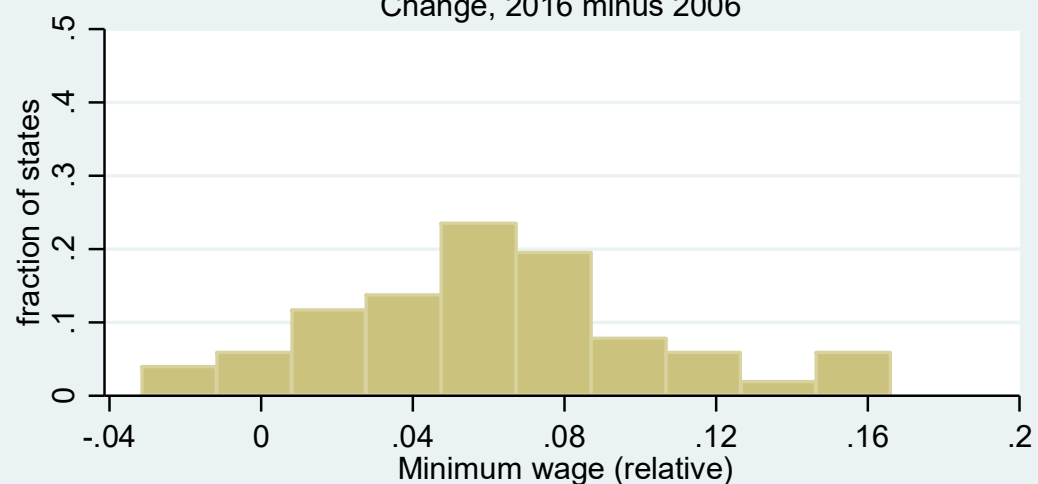

Source: BLS and authors' calculations. Median wage is inflation adjusted (2016 \$), minimum wage measured relative to nominal median wage. 


\section{Appendix Table B1: Full Decomposition of IPT change (2006 base)}

(based on average marginal effects from column 1 of Table 3)

(1)

Years: $\quad \underline{2010}$

(2)

(3)

$\underline{2013} \underline{2016}$

\section{Variables (by category)}

Cyclical

Unemployment effects

$$
0.0165
$$

0.0097

0.0009

Industry Shares

Construction

0.0039

0.0032

0.0023

Manufacturing

$-0.0004$

$-0.0004$

$-0.0004$

Wholesale trade

0.0012

0.0011

0.0018

Retail trade

0.0002

0.0003

0.0003

Transportation/comm/utilities

$-0.0002$

0.0000

0.0005

Information

0.0002

0.0003

0.0003

Financial activities

0.0001

0.0002

0.0002

Professional/business services

$-0.0001$

$-0.0007$

$-0.0008$

Leisure \& hospitality

0.0015

0.0027

0.0031

Education \& health services

0.0038

0.0038

0.0035

Other services

0.0003

0.0001

$-0.0001$

Population Shares (age/gender)

All 16-24

0.0000

0.0000

0.0000

Men 25-34

$-0.0004$

0.0001

0.0006

Women 25-34

$-0.0002$

$-0.0006$

$-0.0009$

Men 35-54

0.0020

0.0035

0.0039

Women 35-54

$-0.0001$

$-0.0003$

$-0.0003$

All 55-64

0.0006

0.0008

0.0008

All 65+

$-0.0007$

$-0.0017$

$-0.0023$

$\underline{\text { Labor Costs }}$

$\ln$ (median real hourly wage)

0.0005

0.0002

0.0004

State Minimum Wage (relative)

$-0.0002$

$-0.0002$

$-0.0001$

$\underline{\text { Year }}$

Year effects

0.0067

0.0042

$-0.0032$

Note: See text (Section VI) for description of decomposition methodology, plus related results in Tables 6 and 7 . 